Research Article

\title{
Streptozotocin-Induced Adaptive Modification of Mitochondrial Supercomplexes in Liver of Wistar Rats and the Protective Effect of Moringa oleifera Lam
}

\author{
María Alejandra Sánchez-Muñoz, ${ }^{1}$ Mónica Andrea Valdez-Solana (iD, 1 \\ Mara Ibeth Campos-Almazán $\mathbb{D}^{1},{ }^{2}$ Óscar Flores-Herrera, ${ }^{3}$ Mercedes Esparza-Perusquía, ${ }^{3}$ \\ Sofia Olvera-Sánchez, ${ }^{3}$ Guadalupe García-Arenas, ${ }^{4}$ Claudia Avitia-Domínguez ${ }^{\mathbb{D}}{ }^{2}{ }^{2}$ \\ Alfredo Téllez-Valencia, ${ }^{2}$ and Erick Sierra-Campos ${ }^{1}{ }^{1}$ \\ ${ }^{1}$ Facultad de Ciencias Químicas, Universidad Juárez del Estado de Durango Campus, Gómez Palacio, DGO, Mexico \\ ${ }^{2}$ Facultad de Medicina y Nutrición, Universidad Juárez del Estado de Durango Campus, Durango, DGO, Mexico \\ ${ }^{3}$ Departamento de Bioquímica, Facultad de Medicina, Universidad Nacional Autónoma de México, Mexico City, Mexico \\ ${ }^{4}$ Facultad de Ciencias de la Salud, Universidad Juárez del Estado de Durango Campus, Gómez Palacio, DGO, Mexico \\ Correspondence should be addressed to Erick Sierra-Campos; ericksier@gmail.com
}

Received 15 November 2017; Accepted 28 December 2017; Published 1 March 2018

Academic Editor: Saad Tayyab

Copyright (C) 2018 María Alejandra Sánchez-Muñoz et al. This is an open access article distributed under the Creative Commons Attribution License, which permits unrestricted use, distribution, and reproduction in any medium, provided the original work is properly cited.

\begin{abstract}
The increasing prevalence of diabetes continues to be a major health issue worldwide. Alteration of mitochondrial electron transport chain is a recognized hallmark of the diabetic-associated decline in liver bioenergetics; however, the molecular events involved are only poorly understood. Moringa oleifera is used for the treatment of diabetes. However, its role on mitochondrial functionality is not yet established. This study was aimed to evaluate the effect of $M$. oleifera extract on supercomplex formation, ATPase activity, ROS production, GSH levels, lipid peroxidation, and protein carbonylation. The levels of lipid peroxidation and protein carbonylation were increased in diabetic group. However, the levels were decreased in Moringa-treated diabetic rats. Analysis of in-gel activity showed an increase in all complex activities in the diabetic group, but spectrophotometric determinations of complex II and IV activities were unaffected in this treatment. However, we found an oxygen consumption abolition through complex I-III-IV pathway in the diabetic group treated with Moringa. While respiration with succinate feeding into complex II-III-IV was increased in the diabetic group. These findings suggest that hyperglycemia modifies oxygen consumption, supercomplexes formation, and increases ROS levels in mitochondria from the liver of STZ-diabetic rats, whereas M. oleifera may have a protective role against some alterations.
\end{abstract}

\section{Introduction}

Mitochondria, which are mainly composed by proteins and lipids, are considered the most complex and the most important organelles of eukaryotic cells. They not only play a leading role in the energy metabolism, but also closely involve in many cellular processes [1]. Moreover, mitochondria are highly dynamic organelles that continuously divide and fuse as well as move within the cell [2]. In addition, it is now well established that the individual respiratory complexes can be organized into supercomplexes, but the composition and abundance of these may vary among organisms and tissues depending on the metabolic and physiological conditions [3-5] as well as on the lipid content of the mitochondrial inner membrane $[6,7]$. However, mitochondria are a source of reactive oxygen species (ROS) which are involved in many pathological scenarios [8] and often play an essential role in physiological cell death mechanisms [9].

Mitochondrial dysfunction has recently been identified as a common metabolic defect associated with diabetes, obesity, and its metabolic complications [10,11]. Previous 
studies have demonstrated that chronic diabetes induced by streptozotocin (STZ) provoked significant alterations in hepatic mitochondrial function which were restored to normality with insulin treatment [12] or with mifepristone (RU 38486) treatment [13]. In addition, it has been postulated that STZ-induced cytotoxicity in HepG2 cells is mediated, at least in part, by the increase in ROS and reactive nitrogen species (RNS) production, oxidative stress, and mitochondrial dysfunction [14]. Moreover, diverse studies suggest that mitochondrial oxidative function was compromised in diabetic and prediabetic humans as evidenced by reduced levels of fatty acid oxidation, insulin-stimulated ATP synthesis, and expression of genes involved in oxidative phosphorylation (OXPHOS) [15-17]. With respect to OXPHOS, activity was suggested that mitochondrial diabetes may also affect the complex $\mathrm{V}$ [18], and it is interesting to mention that, in diabetic patients' muscle, blue native gel electrophoresis revealed a striking decrease in complex I, III, and IV containing supercomplexes [19]. In addition, impairment of pyruvate dehydrogenase complex on the citric acid cycle and glucokinase activity during diabetes has been reported $[19,20]$. These findings can be associated with an increased in ROS production and a decrease in cellular reduced glutathione (GSH) content in STZinduced diabetic rats [21] and diabetic patients [22].

Moringa oleifera is commonly used in folk medicine as an antidiabetic agent via its antioxidant property. Yet, its biological activity is not limited to the antioxidant capacity. In fact, other important biological activities such as hypolipidaemic, antiatherosclerotic, and anticarcinogenic activities of $M$. oleifera leaves and seeds have been reported [23-26]. However, phenolic compounds found in M. oleifera, especially flavonoids, possess both antioxidant and prooxidant properties depending on concentration used. The latter which is exhibited at higher concentrations of phenolic compounds such as quercetin, galangin, taxifolin, catechin, and prenylated flavonoid have been shown to affect mitochondrial energetic processes (see supplementary materials available here) $[27,28]$. In addition, it has been shown that mitochondria are a plausible main target of flavonoids mediating preventive actions against stress and mitochondrial dysfunction-associated pathologies [29]. Recent evidence indicates that $M$. oleifera aqueous leaf extract presents anticancerous effect on A549 cancer cells by affecting mitochondrial membrane potential and ATP levels [30]. More recently, Khan et al. [31] showed that aqueous extract of $M$. oleifera leaf protects pancreas against ROSmediated damage by enhancing cellular antioxidant defenses and minimizing hyperglycemia in STZ-induced diabetes, which might be due to the glucose uptake enhancement in skeletal muscle, insulin secretion stimulation, and alphaamylase and alpha-glucosidase inhibition. Thus, the favorable roles of $M$. oleifera in glucose metabolism and antioxidant system led us to investigate the effects of $M$. oleifera on diabetes-induced mitochondrial changes in liver. The aim of this study was to investigate the protecting effect of $M$. oleifera extract upon STZ-induced mitochondrial dysfunction. To assess the degree of injury of the STZ, both respiratory and enzyme activity parameters were evaluated and compared with the changes in the M. oleiferatreated group.

\section{Materials and Methods}

2.1. Preparation of the Extract. The extract was prepared using $23 \mathrm{~g}$ of dry-ground sample and $260 \mathrm{~mL}$ of $80 \%$ methanolic aqueous solution by successive maceration. The mixture was shaken in a magnetic grid at room temperature for $24 \mathrm{~h}$ and then filtered through Whatman filter paper number 1 . The final extract was concentrated on a rotary evaporator, placed in a deep freezer for $24 \mathrm{~h}$ and lyophilized to obtain a powdered extract that was kept at $-80^{\circ} \mathrm{C}$.

2.2. Ethics Statement. All experiments were performed in compliance with the guideline for the welfare of experimental animals by the National Institutes of Health and in accordance with the guidelines of Institutional Animal Care. This study was approved by the Institutional Animal Ethics Committee at the Faculty of Health Science, UJED.

2.3. Diabetic Model and Treatment. Streptozotocin (STZ) was dissolved in a citrate buffer $(0.1 \mathrm{M}, \mathrm{pH} 4.5)$ and intraperitoneally injected $(55 \mathrm{mg} / \mathrm{kg}$ ) to induce diabetes in rats. Rats injected only with citrate buffer served as control. Type 1 diabetes was confirmed evaluating fasting plasma glucose levels after 5 days of induction; the inclusion criteria to establish diabetes were $200 \mathrm{mg} / \mathrm{dL}$ of fasting plasma glucose. Rats were divided in control (C group), diabetic (D group), and $M$. oleifera-treated diabetic ( $\mathrm{M}$ group) groups. $\mathrm{M}$ group was daily administered with a $200 \mathrm{mg} / \mathrm{kg}$ dose of extract by gavage during 3 weeks, and remaining groups were administered with water as vehicle.

2.4. Isolation and Purification of Mitochondria. The rat liver was collected immediately after euthanasia and homogenized in $100 \mathrm{~mL}$ of a buffer containing $20 \mathrm{mM}$ Tris- $\mathrm{HCl}$, $200 \mathrm{mM}$ mannitol, $50 \mathrm{mM}$ sucrose, $1 \mathrm{mM}$ EDTA, $1 \mathrm{mM}$ PMSF, 1 protease inhibitor tablet, and $0.1 \%$ bovine serum albumin (BSA) ( $\mathrm{pH} \mathrm{7.4;} \mathrm{buffer} \mathrm{A).} \mathrm{Cellular} \mathrm{and} \mathrm{nuclear}$ fractions were removed in the pellet by centrifuging at $3,500 \mathrm{rpm}$ for $10 \mathrm{~min}$ at $4^{\circ} \mathrm{C}$. Mitochondria were obtained by centrifuging the supernatant for $10 \mathrm{~min}$ at $11,000 \mathrm{rpm}$. Then, mitochondria were washed and resuspended in buffer $\mathrm{A}$ without BSA and centrifuged at $11,000 \mathrm{rpm}$ for $10 \mathrm{~min}$. Mitochondria were loaded on a Percoll gradient 15, 23, and $40 \%$ in buffer A without BSA and centrifuged for $35 \mathrm{~min}$ at $25,000 \mathrm{rpm}$ at $4^{\circ} \mathrm{C}[32]$.

2.5. Oxygen Consumption. Oxygen uptake was estimated polarographically using a Clark-type electrode in a $1.5 \mathrm{ml}$ water-jacketed chamber at $37^{\circ} \mathrm{C}$. The mixture contained $250 \mathrm{mM}$ sucrose, $20 \mathrm{mM}$ HEPES, $50 \mathrm{mM} \mathrm{K} \mathrm{HPO}_{4}, 10 \mathrm{mM}$ $\mathrm{H}_{3} \mathrm{PO}_{4}, 10 \mathrm{mM} \mathrm{MgCl}_{2}$, and $1 \mathrm{mM}$ EGTA, 0.1\% BSA (pH 7.4) [33]. Oxygen consumption was stimulated by the addition of $0.1 \mathrm{mM} \mathrm{NADH}$ or $10 \mathrm{mM}$ succinate (in the presence of $2 \mu \mathrm{M}$ rotenone). Otherwise, artificial substrates such as 
ascorbate/TMPD $(10 \mathrm{mM}$ and $100 \mu \mathrm{M}$, respectively, in the presence of $2 \mu \mathrm{M}$ antimycin) were used for complex IV activity, and malonate and $\mathrm{KCN}$ were added to inhibit complex IV and complex II (10 $\mathrm{mM}$ and $5 \mathrm{mM}$, respectively).

2.6. NADH Dehydrogenase and Succinate Dehydrogenase Activities. Activities of complex I (NADH:DCPIP oxidoreductase) and complex II (succinate: DCPIP oxidoreductase) were determined spectrophotometrically at $600 \mathrm{~nm}$ by following the reduction of the artificial electron acceptor 2,6-dichlorophenol-indophenol (DCPIP; $50 \mu \mathrm{M}$; $\left.\varepsilon_{\text {DCPIP }}=21 \mathrm{mM}^{-1} \cdot \mathrm{cm}^{-1}\right)$. Mitochondria were permeabilized with $0.03 \%$ zwittergent and incubated in $10 \mathrm{mM} \mathrm{KH}_{2} \mathrm{PO}_{4}$, $5 \mathrm{mM} \mathrm{MgCl} 2,1 \mathrm{mM} \mathrm{EGTA}$, and $120 \mathrm{mM} \mathrm{KCl}(\mathrm{pH} \mathrm{7.4})$, either with $0.2 \mathrm{mM}$ NADH (complex I) or $2 \mathrm{mM}$ succinate (complex II), plus $0.2 \mathrm{mM}$ methosulfate phenazine (PMS). Mitochondria protein concentration was $1 \mathrm{mg} / \mathrm{ml}$, and the reaction was started by the addition of NADH or succinate [34].

2.7. ATP Synthase Assay. ATP hydrolysis of complex V was measured spectrophotometrically at $25^{\circ} \mathrm{C}$ using a coupled assay to the oxidation of NADH $\left(\varepsilon_{340 \mathrm{~nm}}=6.22 \mathrm{mM}^{-1} \cdot \mathrm{cm}^{-1}\right)$. The assay contained $100 \mu \mathrm{g}$ mitochondrial protein, $10 \mathrm{mM}$ HEPES ( $\mathrm{pH}$ 8.0), $100 \mathrm{mM} \mathrm{NaN}_{3}, 100 \mu \mathrm{M} \mathrm{NO}_{4} \mathrm{Na}, 90 \mathrm{mM}$ $\mathrm{KCl}, 3 \mathrm{mM} \mathrm{MgSO}$; the ATP regenerating system consisted of $5 \mathrm{mM}$ phosphoenolpyruvate, $2 \mathrm{mM}$ ATP, $0.03 \%$ zwittergent, 50 units $/ \mathrm{mL}$ pyruvate kinase, and 30 units $/ \mathrm{mL}$ lactate dehydrogenase. The ATPase reaction was started by the addition of $0.1 \mathrm{mM}$ NADH. Oligomycin $(6 \mu \mathrm{g} / \mathrm{mL})$ was added to inhibit ATPase activity and verify F1F0-ATP synthase integrity; mitochondria were incubated with oligomycin for $30 \mathrm{~min}$ [35].

2.8. Native Electrophoresis. Respiratory complexes and supercomplexes were resolved by native PAGE as reported previously [36]. Purified liver mitochondria $(1 \mathrm{mg})$ were suspended in $50 \mathrm{mM}$ Bis-Tris and $500 \mathrm{mM} \mathrm{6-aminocaproic}$ acid ( $\mathrm{pH}$ 7.0) and solubilized by adding digitonin (detergent : protein ratio of $1: 5$ ). The mixtures were incubated for $30 \mathrm{~min}$ at $4^{\circ} \mathrm{C}$ and centrifuged at $100,000 \mathrm{~g}$ for $30 \mathrm{~min}$. The supernatants were recovered and immediately loaded on a linear gradient polyacrylamide gradient gels $(4-10 \%)$ for Blue Native PAGE (BN-PAGE) or Clear Native PAGE high resolution (hrCN-PAGE).

For BN-PAGE, the anode buffer contained $50 \mathrm{mM}$ BisTris/HCl ( $\mathrm{pH} 7.0$ ); the cathode buffer contained $50 \mathrm{mM}$ tricine and $15 \mathrm{mM}$ Bis-Tris (pH 7.0), and Coomassie (0.02\%). For the hrCN-PAGE, the anode buffer contained $25 \mathrm{mM}$ imidazole/ $\mathrm{HCl}(\mathrm{pH} 7.0)$; while the cathode buffer contained $50 \mathrm{mM}$ tricine, $7.5 \mathrm{mM}$ imidazole, $0.01 \% \quad \beta$ dodecyl $\mathrm{D}$-maltoside, and $0.05 \%$ sodium deoxycholate ( $\mathrm{pH} 7.0$ ), supplemented with Ponceau S red [37]. Gels were run at $4^{\circ} \mathrm{C}$ and $35 \mathrm{~V}$ for $16 \mathrm{~h}$. The molecular weights of the respiratory complexes or supercomplexes were estimated by using digitonin bovine heart mitochondrial complexes as standard: single complex: $\mathrm{I}=1,000 \mathrm{kDa}, \mathrm{V}=750 \mathrm{kDa}, \mathrm{III}_{2}=500 \mathrm{kDa}$,
$\mathrm{IV}=230 \mathrm{kDa}, \quad \mathrm{II}=130 \mathrm{kDa} ; \quad$ supercomplexes: I-III$\mathrm{IV}_{1-4}=1500-2100 \mathrm{kDa}, \mathrm{V}_{2}=1500 \mathrm{kDa}$.

2.9. Complex and Supercomplexes In-Gel Activities. The ingel activity assays were performed as Wittig and Schägger [38] for complex I activity (NADH : methylthiazolyldiphenyl tetrazolium bromide reductase), complex II activity (succinate: methylthiazolyldiphenyl tetrazolium bromide reductase), and complex IV activity (cytochrome $c$ : diaminobenzidine reductase). In all cases, the assays were performed at $20-25^{\circ} \mathrm{C}$ and stopped with $50 \%$ methanol and $10 \%$ acetic acid, after $10-25 \mathrm{~min}$.

The in-gel activity of complex $\mathrm{V}$ was performed in $50 \mathrm{mM}$ glycine (adjusted to $\mathrm{pH} 8.0$ with triethanolamine), $10 \mathrm{mM} \mathrm{MgCl}_{2}, 0.15 \% \mathrm{~Pb}\left(\mathrm{ClO}_{4}\right)_{2}$, and $5 \mathrm{mM}$ ATP. ATP hydrolysis was correlated with the development of white lead phosphate precipitates. The reaction was stopped using 50\% methanol, and subsequently, the gel was transferred to water and scanned against a dark background as described previously [39].

2.10. SDS-Gel Electrophoresis and Western Blot Analysis. Liver mitochondrial proteins $(20 \mu \mathrm{g}$ per well) were separated by SDS-PAGE according to Laemmli [40] in a $10 \%$ polyacrylamide gel under denaturing conditions. Proteins were then transferred from gel to PVDF membrane (Immobilon P; Millipore, Bedford, MA) in a semidry electroblotting system (Bio-Rad) at $25 \mathrm{~V}$ for $50 \mathrm{~min}$. Membranes were blocked in $500 \mathrm{mM} \mathrm{NaCl}, 0.05 \%$ Tween-20, and $20 \mathrm{mM}$ Trisbase ( $\mathrm{pH} 7.5$ ) (TTBS buffer), containing 5\% blotting grade blocker nonfat dry milk. Then, membranes were incubated with antitotal OXPHOS antibody cocktail (at 1/500 dilution). Immunoreactive bands were visualized by enhanced chemiluminescence (Amersham Life Science, Inc.), according to the manufacturer's instructions, using horseradish peroxidase-conjugated antimouse IgG (at $1 / 10,000$ dilution), and densitometric analyses were performed with the software Image Studio Lite version 5.2 (LI-COR Biosciences).

2.11. Protein Determination. The protein levels were estimated by the method described by Lowry et al. using BSA as standard [41].

2.12. Mitochondrial Glutathione Reductase Activity. Glutathione reductase enzymatic activity was recorded by NADPH consumption. Briefly, $50 \mu \mathrm{g}$ of purified mitochondria was placed in a phosphate buffer $(50 \mathrm{mM}, \mathrm{pH} 7.0)$ containing $1 \mathrm{mM}$ GSH and $0.1 \mathrm{M}$ NADPH. NADPH reduction was measured at $340 \mathrm{~nm}\left(\varepsilon_{\mathrm{NADPH}}=6.22 \mathrm{M}^{-1} \cdot \mathrm{cm}^{-1}\right)$.

2.13. Measurement of Glutathione Concentration by HPLC$U V$. To quantify GSH and GSSG concentrations, a standard curve of oxidized and reduced glutathione was used as described by Yilmaz et al. [42]. Mitochondrial samples were centrifuged at $500 \mathrm{rpm}$ for $10 \mathrm{~min}$ and filtered to be injected 
onto a Kromasil ETERNITY C18 column $(4.6 \times 150 \mathrm{~mm})$. Mobile phase containing $10 \mathrm{mM}$ of monobasic sodium phosphate and $2 \%$ methanol $(\mathrm{pH} 3.0)$ was used at a flow rate of $1 \mathrm{~mL} / \mathrm{min}$ in isocratic run. GSH and GSSG eluted from the column were detected at $210 \mathrm{~nm}$.

2.14. Lipid Peroxidation Assay. Mitochondrial lipid peroxidation was estimated by the thiobarbituric acid reactive substances (TBARS) method consisting of TBA-TCA-HCl reaction as described by Buege and Aust [43]. Samples were boiled at $95^{\circ} \mathrm{C}$ for $60 \mathrm{~min}$, followed by a cooling and centrifugation steps at $12,000 \mathrm{rpm}$ for $10 \mathrm{~min}$ at $4^{\circ} \mathrm{C}$. The pink product absorbance (formed when the MDA reacts with TBA) was spectrophotometrically recorded at $532 \mathrm{~nm}$ $\left(\varepsilon_{\mathrm{MDA}}=1.56 \times 10^{5} \mathrm{M}^{-1} \cdot \mathrm{cm}^{-1}\right) . \mathrm{MDA}-\mathrm{TBA}$ adduct peak was calibrated with tert-butyl hydroperoxide simultaneously processed as samples.

2.15. Mitochondrial $\mathrm{H}_{2} \mathrm{O}_{2}$ Measurement. $\mathrm{H}_{2} \mathrm{O}_{2}$ emission was determined by the fluorogenic indicator Amplex Red (Invitrogen) oxidation in presence of horseradish peroxidase as described by Starkov [44]. Fluorescence was recorded in a spectrofluorometer (LS 55 PerkinElmer Life Sciences) with excitation and emission wavelengths of 555 and 581, respectively. Briefly, $300 \mu \mathrm{g}$ of purified mitochondria was added to $1 \mathrm{~mL}$ incubation buffer containing $125 \mathrm{mM} \mathrm{KCl}$, $20 \mathrm{mM}$ Hepes, $0.2 \mathrm{mM}$ EGTA, $2 \mathrm{mM} \mathrm{KH_{2 }} \mathrm{PO}_{4}, 2 \% \mathrm{BSA}$, $1 \mu \mathrm{M}$ Amplex Red, and $4 \mathrm{U}$ horseradish peroxidase ( $\mathrm{pH} 7.2$ ). $\mathrm{H}_{2} \mathrm{O}_{2}$ production was initiated after addition of $5 \mathrm{mM}$ pyruvate, $2.5 \mathrm{mM}$ malate, and $10 \mathrm{mM}$ succinate as substrates and $1 \mu \mathrm{M}$ rotenone, $0.2 \mu \mathrm{M}$ antimycin $\mathrm{A}$, and $5 \mathrm{mM}$ malonate as inhibitors.

2.16. Measurement of Protein Carbonylation. Determination of carbonyl content was followed as Levine et al. [45]. The oxidative damage to proteins was determined by carbonyl groups based on their reaction with 2,4-dinitrophenylhydrazine (DNPH) to form hydrazones. Briefly, $0.5 \mathrm{mg}$ of mitochondria was incubated with $20 \mathrm{mM}$ DNPH solution for $1 \mathrm{~h}$; then proteins were precipitated with $20 \%(\mathrm{w} / \mathrm{v})$ of trichloroacetic acid and redissolved in DNPH. In brief, the proteins were precipitated by the addition of $20 \%(\mathrm{w} / \mathrm{v})$ of trichloroacetate; protein pellet was washed three times with ethanol : ethyl acetate $(1: 1)$ and resuspended in $1 \mathrm{~mL}$ of $6 \mathrm{M}$ guanidine. The absorbance was recorded at $370 \mathrm{~nm}$ $\left(\varepsilon_{\text {Hydrazone }}=22 \times 10^{3} \mathrm{M}^{-1} \cdot \mathrm{cm}^{-1}\right)$.

2.17. Measurement of HO-1 Activity. Fresh livers were placed in prechilled Dounce homogenizer, and cold homogenization buffer containing $100 \mathrm{mM}$ potassium phosphate buffer (pH 7.4), $2 \mathrm{mM} \mathrm{MgCl}_{2}, 250 \mathrm{mM}$ sucrose, and a protease inhibitor cocktail $(10 \mu \mathrm{g} / \mathrm{mL}$ leupeptin, $10 \mu \mathrm{g} / \mathrm{mL}$ trypsin inhibitor, $2 \mu \mathrm{g} / \mathrm{mL}$ aprotinin, and $1 \mathrm{mM}$ PMSF) was added. The homogenate was centrifuged at $10,000 \mathrm{~g}$ for $30 \mathrm{~min}$ at $4^{\circ} \mathrm{C}$, followed by the supernatant centrifugation at $100,000 \mathrm{~g}$ for $60 \mathrm{~min}$ at $4^{\circ} \mathrm{C}$, to obtain the microsomal fraction as a pellet. HO-1 activity was spectrophotometrically measured as described previously [46]. The microsomal fraction $(50 \mu \mathrm{L})$ was added to the reaction mixture $(500 \mu \mathrm{L})$ containing $0.8 \mathrm{mM}$ NADPH, $2 \mathrm{mM}$ glucose-6-phosphate, 0.2 unit of glucose-6-phosphate dehydrogenase, $20 \mu \mathrm{M}$ hemin, $100 \mathrm{mM}$ potassium phosphate buffer ( $\mathrm{pH} \mathrm{7.4),} \mathrm{and} 2 \mathrm{mg}$ of rat liver cytosol as a source of biliverdin reductase. The mixture was incubated at $37^{\circ} \mathrm{C}$ for $60 \mathrm{~min}$ in dark, and samples were left in an ice bath for at least 2 min to stop the reaction. Bilirubin product was determined by calculation from difference in optical density (OD) at $464 \mathrm{~nm}$ and $530 \mathrm{~nm}\left(\mathrm{OD}_{464}-\mathrm{OD}_{530} \mathrm{~nm}\right)$ of the sample. HO activity is expressed as $\mathrm{pmol} / \mathrm{min} / \mathrm{mg}$ protein.

2.18. Data Analysis. The obtained data are represented as mean \pm standard deviation of three independent determinations, using the Sigma Plot software version 11.0. Differences between means were obtained by analysis of variance (ANOVA) and multiple comparison tests. $P$ values $<0.05$ were considered as significant.

\section{Results and Discussion}

The effectiveness of $M$. oleifera extract in alleviating diabetes was assessed in the STZ-induced diabetic model in Wistar rats. In response to STZ, rats showed increased water uptake, increased urine production, increased blood glucose levels, and reduced weight gain (D group $=229 \pm 9.05 \mathrm{mg} / \mathrm{dL}$ and $156 \pm 12 \mathrm{~g}$ ), which were unaltered in the control group (C group $=78 \pm 5.5 \mathrm{mg} / \mathrm{dL}$ and $187 \pm 18 \mathrm{~g}$ ), while $\mathrm{M}$ group significantly alleviated all parameters of diabetes (86 \pm $4.2 \mathrm{mg} / \mathrm{dl}$ and $194 \pm 8 \mathrm{~g}$ ). These results suggest that $M$. oleifera leaf may be a potential agent in the treatment of type 1 diabetes and are agreed with the observations that suggest the beneficial effects of Moringa oleifera supplementation on diabetes $[47,48]$. Hence, these results led us to investigate the valuable effects of the leaf extract on STZ-induced mitochondrial changes, in liver, evaluating STZ injury on both, respiratory and enzyme activities from respiratory chain and some of the antioxidant system comparing them with those from $M$. oleifera treatment.

3.1. M. oleifera Attenuates Oxidant Stress and the Decrease in the Glutathione System in Liver Mitochondria. Diabetic cells and tissues have the capacity to invoke adaptive mechanisms that evolved to defend against oxidative stress [49]. One putative mechanism is a defense system that would protect against ROS into mitochondria. These include the superoxide conversion to hydrogen peroxide $\left(\mathrm{H}_{2} \mathrm{O}_{2}\right)$ by manganese superoxide dismutase (SOD) and scavenging $\mathrm{H}_{2} \mathrm{O}_{2}$ by catalase, glutathione peroxidase (GPx), or peroxiredoxin III [50]. Reduced glutathione $(\mathrm{GSH})$ scavenges $\mathrm{H}_{2} \mathrm{O}_{2}$ via GPx, ubiquitously expressed both in the mitochondria matrix and intermembrane space [51]. In turn, the reduction of oxidized glutathione (GSSG) to GSH is catalyzed by glutathione reductase (GR), which requires NADPH. Thus, increased ROS removal results in increased NADPH turnover. Also, GSH can also be used in conjugation reactions to protect mitochondria enzymes from various toxins, for 
TABLE 1: GSH and GSSG levels by HPLC-DAD and GR enzymatic activity in liver mitochondria from different groups.

\begin{tabular}{|c|c|c|c|c|c|}
\hline Group & $\mathrm{GSH}(\mu \mathrm{mol} / \mathrm{mg}$ protein $)$ & GSSG $(\mu \mathrm{mol} / \mathrm{mg}$ protein $)$ & GSH/GSSG ratio & Total GSH $(\mu \mathrm{mol} / \mathrm{mg}$ protein $)$ & GR (U/min) \\
\hline $\mathrm{C}$ & $174.1 \pm 35.1$ & $4.8 \pm 3.4$ & $36.2 \pm 0.19$ & $178.8 \pm 5.7$ & $267.2 \pm 11.7$ \\
\hline $\mathrm{D}$ & $50.4 \pm 1^{*}$ & $49.8 \pm 1.1^{*}$ & $1 \pm 0.08^{*}$ & $100.2 \pm 1.3^{*}$ & $236 \pm 14.5$ \\
\hline $\mathrm{M}$ & $169 \pm 1.2^{* *}$ & $54.7 \pm 2.2^{* *}$ & $3 \pm 0.05^{* *}$ & $223.7 \pm 2.9^{* *}$ & $366.7 \pm 23.8^{* *}$ \\
\hline
\end{tabular}

$\mathrm{C}=$ control; $\mathrm{D}=$ diabetic; $\mathrm{M}=$ diabetic plus Moringa.${ }^{*}$ Significant difference versus control $(P<0.05) .{ }^{* *}$ Significant difference versus control and diabetic $(P<0.05)$.

TABLE 2: Levels of MDA and carbonyl groups in liver mitochondria from different treatments.

\begin{tabular}{lccc}
\hline Group & MDA (nmol/mg prot) & Carbonyl groups $(\mathrm{nmol} / \mathrm{mg})$ & HO-1 $(\mathrm{pmol} / \mathrm{min} / \mathrm{mg})$ \\
\hline C & $0.4317 \pm 0.009$ & $3.7232 \pm 0.57$ & $40.9 \pm 4.9$ \\
D & $0.5028 \pm 0.06$ & $12.738 \pm 0.28^{\#}$ & $85.7 \pm 2.1^{*}$ \\
M & $0.3851 \pm 0.02^{*}$ & $4.2645 \pm 0.98$ & $105.2 \pm 3.4^{* \#}$ \\
\hline
\end{tabular}

$\mathrm{C}=$ control; $\mathrm{D}=$ diabetic; $\mathrm{M}=$ diabetic plus Moringa. ${ }^{*}$ Significant difference versus diabetic $(P<0.05) .{ }^{*}$ Significant difference versus control $(P<0.05)$.

example, by-products in lipid peroxidation such as 4-hydroxynonenal (HNE) [52].

To assess the influence of STZ injection on redox state, mitochondrial GSH levels and GR of liver were examined. A single dose of STZ caused a significant decrease in GSH and total GSH contents of diabetic rats (Table 1). Basal levels of total $\mathrm{GSH}$ were $178.8 \pm 5.7 \mu \mathrm{mol} / \mathrm{mg}$ of protein in control mitochondria, whereas total GSH levels in isolated mitochondria from STZ-treated rats (D group) were significantly decreased by $70 \%$ compared with control $(100.2 \pm$ $1.3 \mu \mathrm{mol} / \mathrm{mg}$ of protein). In contrast, $M$. oleifera treatment prevented a STZ-mediated decrease in GSH levels (M group $=223.7 \pm 2.9 \mu \mathrm{mol} / \mathrm{mg}$ of protein), which correspond to an increase of $25 \%$ compared with $\mathrm{C}$ group. It is worth to mention that $M$ group rats showed a significant increase in values of GSH, total GSH (2 times), and GSH/GSSG ratio $(P<0.05)$ compared with $\mathrm{D}$ group. However, the $\mathrm{M}$ group ratio was 12 times reduced with respect to $C$ group (Table 1). One possible explanation for this phenomenon may be the inactivation of mitochondrial GR activity. However, as observed in Table 1, STZ administration did not alter the GR activity in liver mitochondria when compared with control rats. However, $M$ group samples significantly increased GR activity when compared with values of $\mathrm{D}$ and $\mathrm{C}$ groups (Table 1). Hence, these results show that GR inactivation is not the main mechanism of GSSG accumulation into the mitochondria.

The oxidative stress implications in diabetes pathogenesis are suggested to be produced not only by ROS generation but also by a nonenzymatic protein glycation, autoxidation of glucose, impairment of antioxidant enzymes, and peroxides formation. Therefore, GSH level decline is associated with oxidative damage to macromolecules, such as lipids and proteins. ROS-mediated lipid peroxidation is a crucial factor in the development of diabetic liver complications. In addition, GSH depletion induces heme oxygenase-1 (HO-1), a key microsomal enzyme in heme degradation to carbon monoxide (CO), iron $\left(\mathrm{Fe}^{2+}\right)$, and biliverdin; this latter being converted into bilirubin by the cytosolic biliverdin reductase $[53,54]$. Moreover, some observations suggest the cytoprotective mechanism of $\mathrm{HO}-1$ against oxidative stress involving an increase in mitochondrial carrier levels and antiapoptotic proteins as well as in cytochrome $c$ oxidase activity [55].

In order to evaluate this possibility, we measure carbonyls concentration, lipoperoxidation, and HO-1 activity. As observed in Table 2, C group showed the lowest levels of carbonylation and MDA. In contrast, STZ treatment increased lipid peroxidation and protein carbonyl content (Table 2). Besides, $M$ group showed a significant decrease in lipoperoxidation in liver mitochondria $(P<0.05)$ when compared with $\mathrm{D}$ group. The carbonylation level in mitochondria of $M$ group was significantly lower and showed significant difference when compared with D group (Table 2 ). In contrast, $M$. oleifera extract administration did not prevent the HO-1 induction provoked by STZ, where its enzymatic activity remained significantly higher. Our results clearly demonstrated that $M$. oleifera significantly suppressed both lipoperoxidation and protein carbonylation. However, M. oleifera did not lower the HO-1 activity, and little is known about the molecular mechanisms responsible for its activation, which requires further investigation.

It has been reported that $M$. oleifera exhibits bifunctional antioxidant properties related to its ability to react directly with ROS and to induce antioxidant enzymes expression such as superoxide dismutase, catalase, glutathione reductase, and glutathione peroxidase [56-58]. We confirmed previous data and showed that Moringa not only decreased lipoperoxidation and protein carbonylation levels in rat livers but also increased HO-1 activity, parameters associated with a cytoprotective mechanism against oxidative stress [59].

3.2. Effects of STZ and $M$. oleifera on Oxygen Consumption. Although many previous studies have reported pharmacological properties of $M$. oleifera, particularly as antioxidant and antidiabetic properties that may provide benefits for diabetic patients $[25,60,61]$, there are no reports that show $M$. oleifera extract effect on mitochondria functionality. To determine the changes of mitochondrial respiration in STZ-induced diabetic rats and $M$. oleifera 


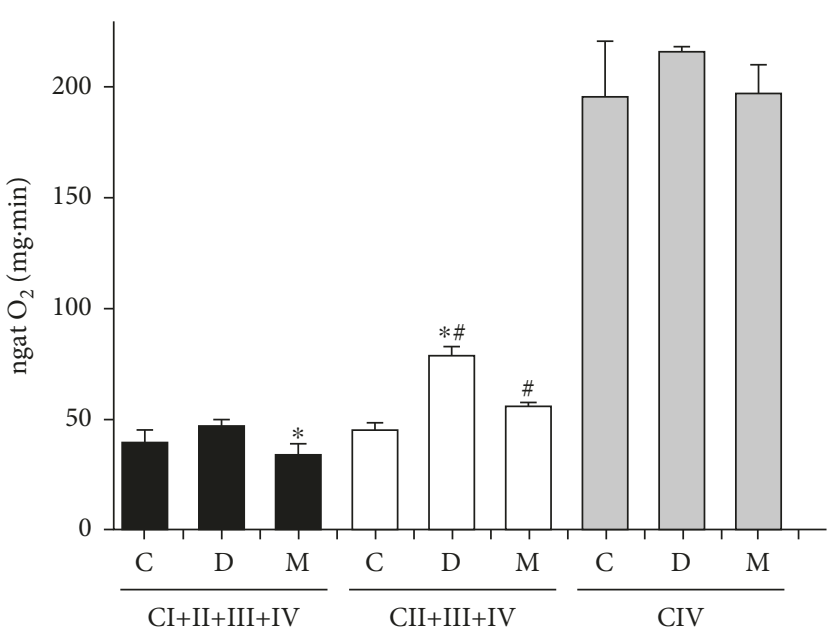

(a)

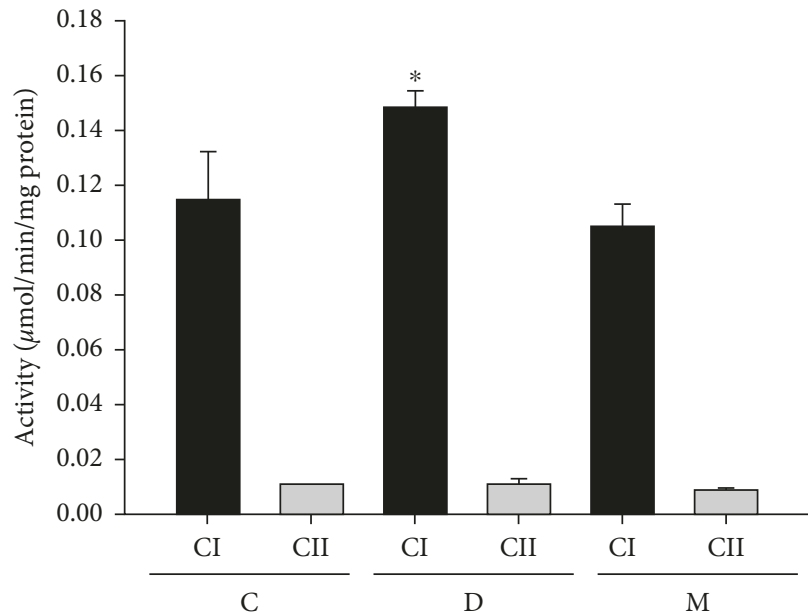

(b)

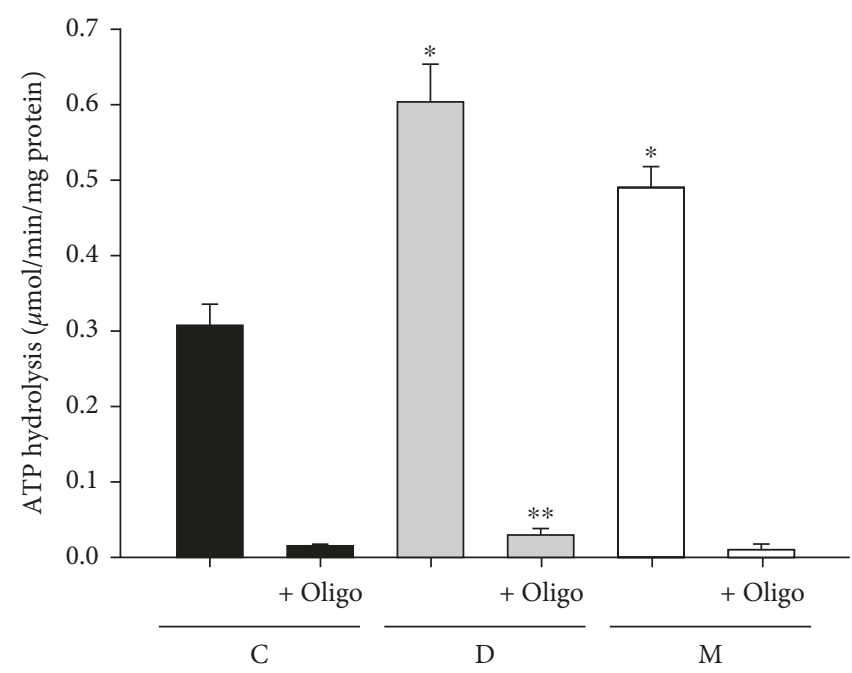

(c)

Figure 1: Moringa oleifera effect on mitochondrial respiratory chain. (a) Oxygen consumption $\left({ }^{*} P<0.05\right.$ versus $D ;{ }^{\#} P<0.05$ versus C); (b) enzymatic activity of complex I and II $\left({ }^{*} P<0.05\right.$ versus $C$ and $\left.M\right) ;\left(\right.$ c) $\mathrm{F}_{1} / \mathrm{F}_{0}$ ATPase activity $\left({ }^{*} P<0.05\right.$ versus $C$ and $M$; ${ }^{* *} P<0.05$ versus $\mathrm{M}+$ oligo) from liver mitochondria. C: control; D: diabetic; M: Moringa-treated diabetic groups.

protective effect, we measured the mitochondrial respiratory chain using Clark-type oxygen electrode and determined enzymatic activity of each complex by spectrophotometric methods.

Figure 1(a) shows the respiratory activity of all groups in presence of complex I, II, and IV substrates. The combination of pyruvate + malate indirectly investigates the monocarboxylate and dicarboxylate transporters and the pyruvate dehydrogenase activities. The substrate combination produces NADH which donates electrons to complex I. In $\mathrm{D}$ group, the state 4 respiration with pyruvate + malate was not affected. However, Moringa treatment resulted in $15 \%$ decrease in the state 4 respiration. By contrast, succinate donates electrons to $\mathrm{FAD}^{+}$in complex II and yields significantly high respiration state 4 rates in both $\mathrm{D}$ and $\mathrm{M}$ groups compared with $\mathrm{C}$ group. Otherwise, in diabetic rats, state 4 respiration with succinate increased by $80 \%$ compared with control rats. The observed change in the diabetic animals was rectified by Moringa treatment (Figure 1(a)). Additionally, functional analysis of complex IV (cytochrome c oxidase) maximal activity was assayed with ascorbate (Asc) and $\mathrm{N}, \mathrm{N}, \mathrm{N}^{\prime}, \mathrm{N}^{\prime}$-tetramethyl-p-phenylenediamine (TMPD), which is an artificial redox mediator that assists the electron transfer from ascorbate to cytochrome $c$. Complex IV respiration was calculated as the portion sensitive to cyanide potassium (KCN), a specific inhibitor of cytochrome $c$ oxidase (Figure 1(a)), revealing no differences among all experimental groups.

Additionally, we measured the specific activities of respiratory chain complexes in liver mitochondria. Spectrophotometric analysis showed a significant increase in complex I and ATPase activities in D group (Figure 1(c)), while Moringa treatment was effectively reversing this alteration nearly to control values. Complex II showed no significant change in mitochondrial fraction of $\mathrm{D}$ group (Figure 1(b)). These data show that individual activities of 
mitochondrial electron transport chain (ETC) enzymes were not negatively modified in diabetic treatment. In addition, the respiratory properties of $D$ and $M$ groups have approximately 1.5-2 times succinate-respiratory rates compared with that of $\mathrm{C}$ group. Therefore, our results suggest that respiratory complex activities were not decreased in liver mitochondria in STZ-induced diabetic rats. These findings, which may appear, at first glance, contradictory, may be interpreted in terms of higher ETC efficiency, thus, avoiding energy losses by electron leakage in response to change in physiological functions and body energy requirements; ETC undergoes some modifications either during pathology development or disease [62]. In addition, several studies concerning STZ-treated rats have been performed with animals of different strains and different amounts of STZ $[63,64]$. In addition, in isolated hepatocytes, increasing glucose concentration does not increase $\Delta \mu_{\mathrm{H}+}$, mitochondrial respiratory rate, or cytosolic $\mathrm{NADH} / \mathrm{NAD}^{+}$ ratio; instead, most of glucose excess is converted to glycogen [65]. In fact, some authors have recently suggested that mitochondria overstimulation is a probable risk factor for insulin resistance, while moderate mitochondrial dysfunction may actually be protective under certain conditions, suggesting the mitochondrial modulation as a prospective therapy for metabolic diseases [66]. For this reason, it is important that future research clarifies the true energy functional state of isolated mitochondria from diabetic animals [67].

3.3. Modulation of Mitochondrial Complexes by STZ. As mitochondrial content can substantially impact on respiratory capacity, protein components of individual respiratory complexes were quantified. To test whether hyperglycemia and $M$. oleifera extract altered the composition of the ETC, we analyzed the expression level of nuclear-encoded mitochondrial complex I subunit NDUFB8, complex II subunit SDHB, complex III UQCRC2, complex IV MTCO1, and complex V ATP5A of each group. Interestingly, in diabetic rats, the NDUFB8 subunit resulted in an increase of complex I expression, while complex II and III were unaltered (Figure 2). These data which resulted in increased expression of NDUFB8 and MTCO1 support the suggestion that increased activity of mitochondrial respiratory chain could result from a proteome alteration leading to modulation of expression/activity of a range of mitochondrial components. More importantly, an upregulation of hepatic CI-NDUFB8 and CIV-MTCO1 was found in diabetic rats, consistent with changes in-gel activity of these complexes. Thus, it is plausible that increased NDUFB8 and MTCO1 contents observed in the STZ group, resulting from diabetes mellitus type 1, may account, in part, for the mitochondrial morphological changes observed, which could have downstream effects on mitochondrial functionality leading to hepatic dysfunction.

3.4. Loss of Redox State Does Not Destabilize Mitochondrial Supercomplexes. It is now widely accepted that mitochondrial respiratory chain is organized with stable and functional entities called supercomplexes (SC) [68]. SC consist of various ratios of copies of individual complexes (I, III, IV, and $\mathrm{V}$ ) to form stable, supramolecular structures; for instance, $\mathrm{CI}$ forms a supercomplex with $\mathrm{CIII}_{2}$ and $\mathrm{CIV}$ (known as the respirasome), as well as with $\mathrm{CIII}_{2}$ alone (SC I+ $\left.\mathrm{III}_{2}\right)$. $\mathrm{CIII}_{2}$ forms a supercomplex with $\mathrm{CIV}\left(\mathrm{SC} \mathrm{III}_{2}+\mathrm{IV}\right)$, and $\mathrm{CV}$ forms dimers $\left(\mathrm{CV}_{2}\right)$. In addition, another recent advance is that the discovery of respiratory megacomplex $\left(\mathrm{MC} \mathrm{I}_{2} \mathrm{III}_{2} \mathrm{IV}_{2}\right)$ represents the highest-order assembly of respiratory complexes [69], and it allows mitochondria to respond to energy requiring conditions and to minimize ROS generation during electron transfer reactions [70], as well as the sequestering of vulnerable sites of mitochondrial complexes from oxidative damage as a protective mechanism that prevents tight interactions between the individual complexes [71].

It is fairly well established in rectus abdominis muscle of diabetic obese patients. BN-PAGE revealed a striking decrease in complex I, III, and IV containing mitochondrial SC [72]. According to these results, Lenaz and Genova [71] suggest that oxidative stress acts primarily by disassembling supercomplex associations thereby establishing a vicious circle of oxidative stress and energy failure, ultimately leading to cell damage and disease.

It is interesting to mention that there are diverse specific regulatory proteins for the supramolecular organization of individual complexes that include CIV [73], respiratory SC factors 1 and 2 (Rcf1 and 2) [74], protein Cox interacting (Coi) [75], and COX7a2L [76]. These proteins downregulation can impair the formation of SC; for instance, some studies show that diverse pathologies decrease CIV subunit levels affecting stoichiometry and assembly of SC $[77,78]$. In addition, diabetes induces mitochondrial genome damage by an increased free radical production depleting antioxidant status [79]. Moreover, other structural components as cardiolipin have been shown to be crucial for functionality and SC formation and might be involved in the pathophysiology of diabetes [80]. Thus, the impact of complex IV failure and other enzymes may cause an energy crisis due to a lower ATP synthesis and an increased ROS production.

Figure 3(a) shows the Coomassie blue staining of the gels for all treatments and the colorimetric enzymatic staining of NADH, Succinate, COX, and ATPase complexes after detergent extraction and BN-PAGE or hrCN-PAGE (only for $\mathrm{CV}$ ). Figure 3(b) clearly indicates that the major form of supercomplexes is present in all samples. In contrast, the amount of free complex I and IV were decreased in D group, and these values did not change in mitochondria isolated from $M$ group. Otherwise, the in-gel activity of complex II was significantly lower in C group compared with those in the $\mathrm{D}$ and $\mathrm{M}$ groups. In addition, the brown bands indicate the presence of complex IV in all groups and its increase in D group (Figure $3(\mathrm{~d})$ ). On the other hand, in-gel ATP hydrolysis/lead phosphate precipitation assay revealed bands representing the $\mathrm{F}_{1} \mathrm{~F}_{0}$ monomer and $\mathrm{F}_{1} \mathrm{~F}_{0}$ dimer bands in Figures 3(e) and 3(f) showing the same functional patterns as the in-solution assays, indicating the level of intrinsic activity driven by complex V. In support, we have shown by comparing the in-gel enzyme activities that the ATPase 


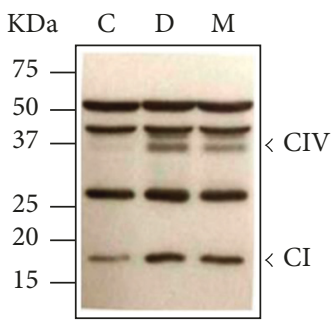

(a)

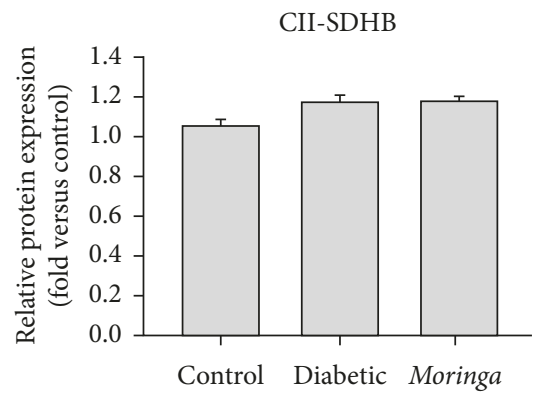

(c)

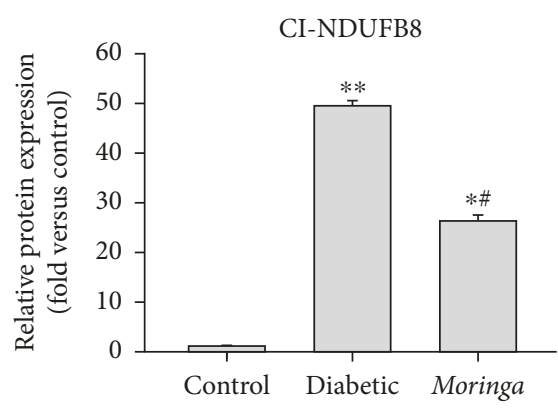

(e)

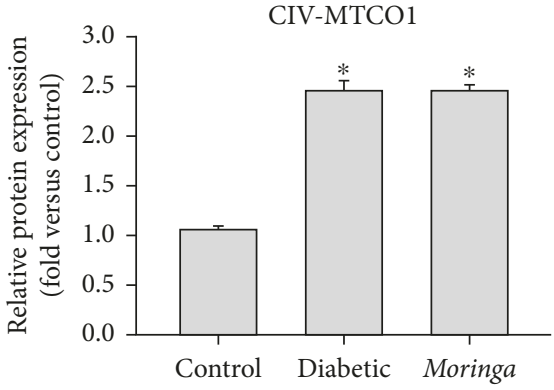

(b)

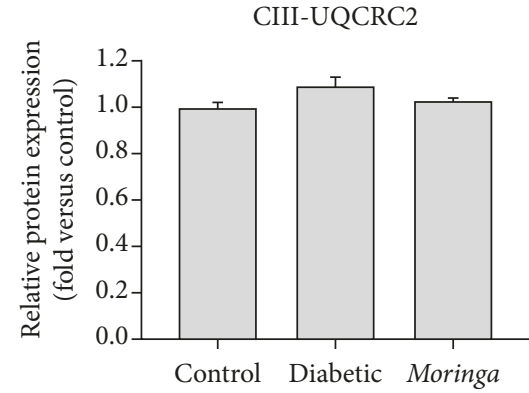

(d)

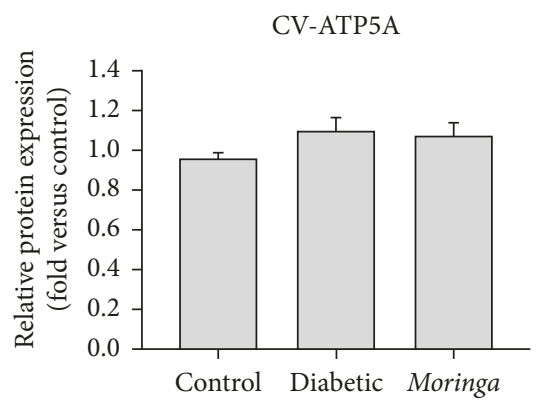

(f)

FIGURE 2: Characterization of OXPHOS proteins expressed in liver mitochondria during diabetes. (a) OXPHOS cocktail specificity demonstrated by a Western blot from liver-isolated mitochondria of diabetic rats and treated with Moringa extract. Relative expression of (b) MTC01 subunit of CIV, (c) SDHB subunit of CII, (d) UQCRC2 subunit of CIII, (e) NDUFB8 subunit of CI, and (f) ATP5A subunit of CV was performed by densitometric analysis from gel. Molecular mass standards are shown on the left panel of the gel. C: control; D: diabetic; M: Moringa-treated group. Data are shown as mean band density normalized relative to UQCR2. Significant differences are represented by ${ }^{*} P<0.05$ versus $C ;{ }^{\#} P<0.05$ versus $D$.

activity of the $\mathrm{F}_{1} \mathrm{~F}_{0}$-ATP synthase is specifically and significantly increased in D group when compared with $\mathrm{C}$ group.

Our results are concerned with the changes in the amount of CIV subunits; for example, Cox6b1 is involved in the regulation of mitochondrial function by promoting SC formation, suggesting its antiaging effects of calorie restriction [81]. In addition, heart failure in dogs induced by coronary microembolism resulted in loss of complex IV containing SC of the electron transport chain [77, 78]. Similarly, in RAW 264.7 macrophages, knockdown of either subunit cytochrome $c$ oxidase $(\mathrm{CcO}) \mathrm{Vb}$ or $\mathrm{CcO}$ IV resulted in a significant decrease in $\mathrm{CcO}$ containing supercomplexes [78]. Liver mitochondria from ethanol-treated rat also showed a lower level of supercomplexes with a concomitant loss of $\mathrm{CcO}$ protein [82]. Therefore, complex IV has been shown to be necessary for maintaining the stability of complex I in SC, as shown in mouse fibroblast cell lines, where a reduced expression of subunit IVil or nonsense mutation in subunit I not only resulted in lower $\mathrm{CcO}$ content but also caused significant reduction in complex I [83]. Structural defects in complex III also affected the amount of complex I, whereas chemical inhibition did not. Patients with defects in cytochrome $b$ not only lose complex III but also show decreased amounts of complex I, while maintaining a normal enzymatic activity [84]. Conversely, the disruption of complex I function caused by nonsense mutations in NDUFS4, a subunit of this large multimeric complex, led to the partial loss of complex III activity in skin fibroblast cultures obtained from Leigh-like patients [85, 86]. However, defects in the complex I subunit ND5 did not cause a loss of complex III in the I-III supercomplex [87]. 


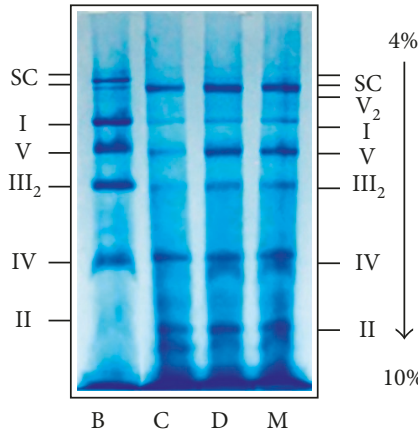

(a)

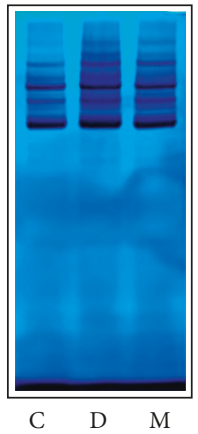

(b)

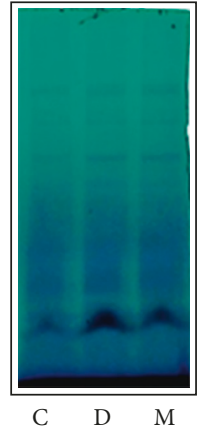

(c)

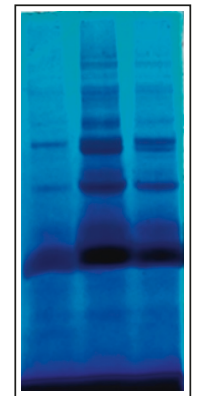

C $\quad$ D $\quad$ M

(d)

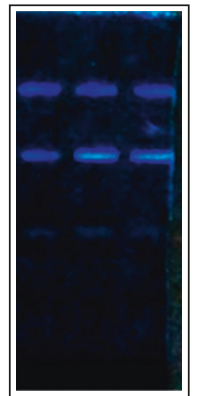

C $\quad$ D $\quad$ M

(e)

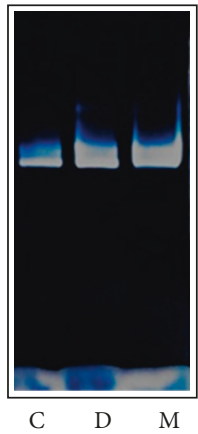

(f)

FIGURE 3: Electrophoretic representative pattern of liver mitochondrial solubilized of the different groups ( $5 \mathrm{~g}$ de digitonin/g protein). (a) Blue native polyacrylamide gel electrophoresis (BN-PAGE) stained with Coomassie blue; (b) complex I in-gel activity; (c) complex II ingel activity; (d) complex IV in-gel activity; (e) complex IV in-gel activity; (f) high resolution clear native polyacrylamide gel electrophoresis (hrCN-PAGE) of complex V. B: bovine heart solubilized mitochondria (positive control); C: control; D: diabetic; M: Moringa-treated diabetic groups.

\section{5. $\mathrm{H}_{2} \mathrm{O}_{2}$ Production by Liver Mitochondria Oxidizing} Complex I and Complex II Substrates. Several studies have reported that ROS overproduction by mitochondrial ETC is responsible for hyperglycemia-induced oxidative stress and the pathogenesis of diabetic complications [88, 89]; however, it is not clear whether mitochondria of diabetic origin really generate ROS independently of the surrounding diabetic milieu. Herlein et al. [90] showed that the gastrocnemius, heart, and liver mitochondria of STZ-diabetic rats were not irrevocably altered to produce superoxide excess either by complex I or complex III. Moreover, gastrocnemius and heart mitochondria demonstrated an increased respiratory coupling, instead of a decrement. In addition, mitochondria of insulin-deficient diabetic rats did show signs of ROS overproduction. Thus, the detailed molecular mechanism and sites of ROS generation during diabetes are controversial.

In isolated mitochondria, the rate of mitochondrial ROS generation is directly governed by membrane potential $(\Delta \Psi \mathrm{m})$ and $\mathrm{pH}$ gradient across the inner membrane, favored only by a state 4 condition [91]. Hence, $\mathrm{H}_{2} \mathrm{O}_{2}$ production rate was measured in liver mitochondria using fluorescent dye Amplex Red and pyruvate plus malate or succinate, as complex I-III and II-III linked substrates, respectively, and the results are shown in Figure 4. Data presented in Figure 4 (a) show that the major source of ROS is complex I for liver mitochondria of $\mathrm{C}$ group, using pyruvate plus malate as substrate, reflecting the generation of superoxide anion. In contrast, with $\mathrm{M}$ group-isolated mitochondria oxidizing succinate in state 4 produced 6 times more ROS compared with other treatments (C and D groups) (Figure 4(b)). Therefore, the mitochondrial ROS production rates varied dramatically among the three experimental groups in response to addition of respiratory inhibitors.

At the level of ROS formation, all groups have the same basal formation using malate plus pyruvate or succinate, but the addition of respiratory inhibitors had a varied effect on ROS production in the different groups. In case of the $\mathrm{C}$ group, the addition of rotenone and antimycin stimulated
ROS production by using pyruvate and malate (Figure 4(a)). However, in both $\mathrm{D}$ group and $\mathrm{M}$ group, the addition of rotenone has no effect, while antimycin caused only a slight increase in ROS formation (Figure 4(a)). Nevertheless, with succinate, inhibitors have a different pattern. In the $\mathrm{C}$ group, the addition of rotenone causes no effect on ROS production, and antimycin favors its increase; but in this case, malonate has no effect (Figure 4(b)). However, in the diabetic group, antimycin has a greater effect on ROS production than control, and malonate adversely affects ROS formation (Figure 4(b)).

Finally, $M$ group sensitivity to individual training inhibitors was unaltered in case of rotenone and malonate, but adding antimycin in this treatment favored ROS production (Figure 4(b)). Thus, measurements of ROS with Amplex Red cannot be used for sites of ROS generation from liver mitochondria treated with STZ and/or M. oleifera. This situation could be attributable to experimental conditions because complex I (rotenone), complex II (malonate), and complex III (antimycin A) inhibitors have been commonly used. However, the final concentration being used is not stationary, causing experimental errors that are different from one method to other. In addition, it is necessary to use other respiratory inhibitors, as stigmatellin and myxothiazol. No obstant, this does not deny other possible explanations that can affect ROS production as differences in the stoichiometry-activity ratios of the respiratory complexes [92], the susceptibility to proton pump slip at complex IV [93], or other mechanisms.

Damage to complex I, the most vulnerable ETC complex, increases ROS production, leading to a vicious circle of further mitochondrial dysfunction. It is important to note that complex I injury has a stronger impact on mitochondrial function compared with the damage to other complexes because mitochondria possess smaller amounts of complex I than other ETC complexes [94]. Superoxide production by complex $\mathrm{I}$ is much higher during reverse electron transport from succinate to $\mathrm{NAD}^{+}$[95]. In addition, it was found that defective complex I produces more ROS 


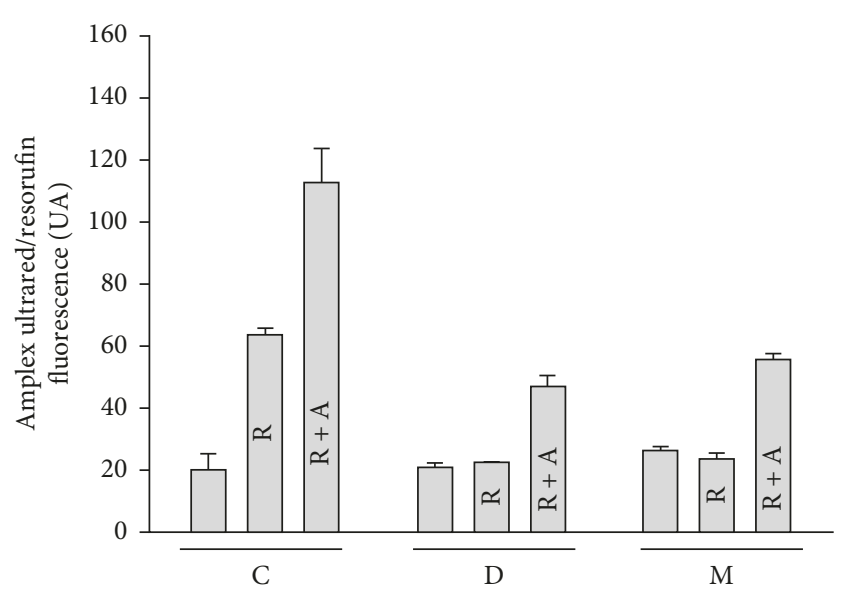

(a)

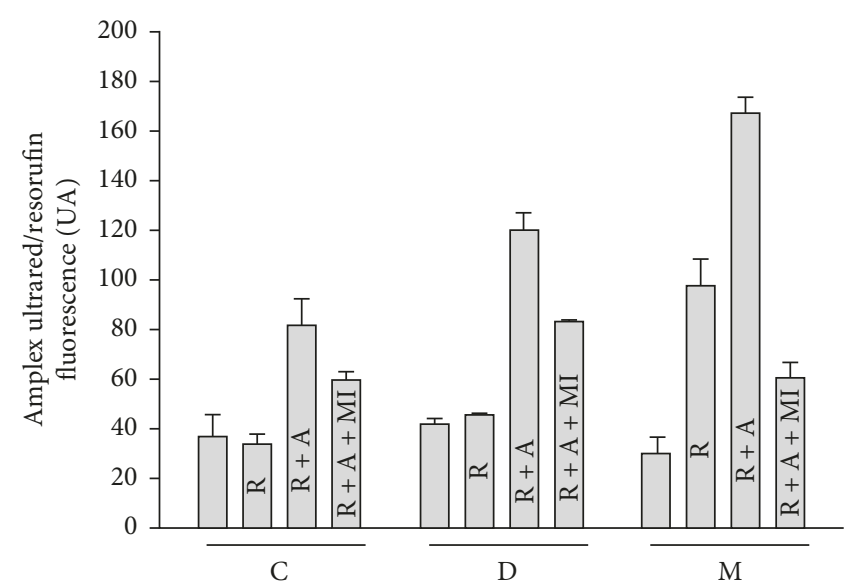

(b)

FIgURE 4: $\mathrm{H}_{2} \mathrm{O}_{2}$ production by mitochondrial respiratory chain measured by Amplex Red (UA) in liver mitochondria from different treatments (C: control; D: diabetic; M: Moringa-treated diabetic groups) oxidizing (a) pyruvate plus malate or (b) succinate as substrates and the effects of respiratory chain inhibitors (R: rotenone; A: antimycin A; Ml: malonate). Mitochondria were studied during state 4 respiration. To correct for the increase in background fluorescence of the Amplex Red/HRP detection system overtime, fluorescence was monitored for a period of ten minutes. This background was subtracted from resorufin trace. Data are means $\pm \operatorname{SEM}(n=5)$.

[96], suggesting that structural modifications of the enzyme may play a crucial role in ROS production process. Recently, it was reported that pancreatic mitochondrial complex I showed aberrant hyperactivity in type 1 and 2 STZ-diabetic mice and rat and in cultured $\beta$ cells [97]. Further experiments focusing on STZ-induced diabetes in rats revealed that complex I's hyperactivity could be attenuated by metformin. Interestingly, in this study, no changes were reported in complex I activity in brain, liver, and heart by BN-PAGE [97]. However, the reason why complex I activity did not exhibit detectable increases in these tissues is unknown.

Our results in Figure 1(b) show that complex I activity was significantly higher in diabetes than in healthy individuals. This increased activity was apparently contributed by an increased NDUFB8 subunit protein content as shown in Figure 2(e). Moreover, the complex I hyperactivity also imposed pressure in complex IV (Figures 2(b) and $3(\mathrm{~d})$ ). These findings suggest that these elevated activities could be attributed for ROS production, given that higher ETC activity can also increase mitochondrial ROS generation $[98,99]$. However, our results on specific sites of ROS generation along with ETC are controversial (Figure 4). This may explain why in some tissues seem that inhibition of electron transfer at complex I (by rotenone) may generate an increase in radical formation, whereas, in others, rotenone will reduce radical generation by preventing passage of electron further into the distal part of the chain. However, the basis for such a difference is obscure and presumed to be related to $\Delta \Psi m$ changes and radicals leakage across the membranes [100].

Polyphenols have been traditionally viewed as antioxidants; however, increasing evidence has emerged supporting the ability of certain polyphenols to exert numerous ROSscavenging independent actions. Then all these natural compounds modulate mitochondrial functions by inhibiting organelle enzymes or metabolic pathways, by altering the production of ROS and modulating the activity of transcription factors which regulate the expression of mitochondrial proteins [101]. Thus, some particular polyphenols are now recognized as molecules capable of modulate pathways that define mitochondrial biogenesis (i.e., inducing sirtuins), mitochondrial membrane potential (i.e., mitochondrial permeability transition pore opening and uncoupling effects), mitochondrial electron transport chain and ATP synthesis (i.e., modulating complex I to $\mathrm{V}$ activity), intramitochondrial oxidative status (i.e., inhibiting/inducing ROS formation/removal enzymes), and ultimately mitochondrial-triggered cell death (modulating intrinsic apoptosis) (review in [102]). Thus, some studies have indicated that mitochondria may be the target organelle of phenolic compounds [103, 104]. Recently, it was reported that galangin (natural flavonoid) could maintain liver mitochondrial function in diabetic rats through oxidative stress reduction and both antioxidant enzymes and respiratory complexes activities enhancement [79]. Therefore, the likely role of mitochondrial ROS in diabetes has led to efforts for developing effective antioxidant compounds targeted to mitochondria.

This study was designed to investigate the protective effect of M. oleifera on liver bioenergetics and to elucidate its potential mechanism. M. oleifera resulted in a well-preserved mitochondrial redox potential, significantly by elevating heme oxygenase- 1 and decreasing ROS formation and lipoperoxidation. These observations indicated that STZinduced mitochondrial oxidative damage was remarkably attenuated. Thus, to our knowledge, we have shown for the first time that $M$. oleifera extract modulates mitochondrial respiratory activity, an effect that may account for some of the protective properties of phytochemicals. These effects may be of physiological significance since it seems that some phytochemicals are concentrated into mitochondria. The 
results also support a pharmacological use of $M$. oleifera extract in drug to reduce mitochondrial damage in vivo. However, the details about mechanism of action require further investigation.

\section{Conclusions}

We provide experimental evidence indicating that $M$. oleifera extract targeting mitochondria can be used therapeutically to alleviate diabetes. Therefore, it will be important to identify regulatory proteins involved in the adjustment of respiratory chain complex organization/activity in response to altered redox state. In liver, the alteration of mitochondrial enzymatic activities and oxidative stress induced by STZ suggested of a compensatory response. In addition, $M$. oleifera extract upregulated mitochondrial genes linked with respiratory chain. Our data show an increased mitochondrial function and activity/expression of respiratory complexes in liver of STZ-diabetic rats, which can be normalized by $M$. oleifera at levels that do not markedly alter the consequences of hyperglycemia.

\section{Conflicts of Interest}

The authors declare no conflicts of interest.

\section{Authors' Contributions}

Erick Sierra-Campos, Mónica Andrea Valdez-Solana, and Óscar Flores-Herrera contributed to conceptualization, literature review, and writing the original draft. María Alejandra Sánchez-Muñoz, Mara Ibeth Campos-Almazán, and Guadalupe García-Arenas conducted the animal studies and performed the experiments. Erick Sierra-Campos, María Alejandra Sánchez-Muñoz, Mercedes Esparza-Perusquía, Sofia Olvera-Sánchez, and Óscar Flores-Herrera analyzed the data. Óscar Flores-Herrera, Alfredo Téllez-Valencia, Claudia Avitia-Domínguez, and Mónica Andrea ValdezSolana contributed reagents/material/analysis tools. María Alejandra Sánchez-Muñoz and Erick Sierra-Campos wrote the paper. All authors read and approved the final manuscript.

\section{Acknowledgments}

The authors would like to express their sincere gratitude to the Consejo Nacional de Ciencia y Tecnología (Conacyt, México) for financial support to Erick Sierra-Campos (Grant 268184). The authors thank Héctor Vázquez-Meza for providing technical assistance. María Alejandra Sánchez Muñoz is also grateful to Conacyt, México, for the financial support for her Masters studies (Grant 601630). The authors are also grateful to the Mexican Moringa oleifera producers (Akuanandi) for providing all samples for this study.

\section{Supplementary Materials}

Figure S1: Possible mitochondrial processes that are modulated by Moringa oleifera extract. It is now well established that the individual mitochondrial respiratory complexes can be organized into supercomplexes, but the composition and abundance of these may vary among organisms and tissues depending on the metabolic and physiological conditions. Alteration of mitochondrial electron transport chain is a recognized hallmark of the diabetic-associated decline in liver bioenergetics; however, the molecular events involved are only poorly understood. Moringa oleifera is used for the treatment of diabetes. However, its role on mitochondrial functionality is not yet established. This study was aimed to evaluate the effect of $M$. oleifera extract on supercomplex formation, ATPase activity, ROS production, GSH levels, lipid peroxidation, and protein carbonylation. The levels of lipid peroxidation and protein carbonylation were increased in the diabetic group. However, the levels were decreased in M. oleifera-treated diabetic rats. Analysis of in-gel activity showed an increase in all complexes activities in the diabetic group, but spectrophotometric determinations of complex II and IV activities were unaffected in this treatment. However, we found an oxygen consumption abolition through complex I-III-IV pathway in the diabetic group treated with Moringa. Respiration with succinate feeding into complex II-III-IV was increased in the diabetic group. We have shown for the first time that $M$. oleifera extract modulates mitochondrial respiratory activity, an effect that may account for some of the protective properties of phytochemicals. These effects may be of physiological significance since it seems that some phytochemicals are concentrated into mitochondria. The results also support a pharmacological use of $M$. oleifera extract in drug to reduce mitochondrial damage in vivo. (Supplementary Materials)

\section{References}

[1] L. D. Osellame, T. S. Blacker, and M. R. Duchen, "Cellular and molecular mechanisms of mitochondrial function," Best Practice \& Research Clinical Endocrinology \& Metabolism, vol. 26, no. 6, pp. 711-723, 2012.

[2] D. C. Chan, "Mitochondria: dynamic organelles in disease, aging, and development," Cell, vol. 125, no. 7, pp. 1241-1252, 2006.

[3] C. Greggio, P. Jha, S. S. Kulkarni et al., "Enhanced respiratory chain supercomplex formation in response to exercise in human skeletal muscle," Cell Metabolism, vol. 25, no. 2, pp. 301-311, 2017.

[4] S. J. Ramírez-Aguilar, M. Keuthe, M. Rocha et al., "The composition of plant mitochondrial supercomplexes changes with oxygen availability," Journal of Biological Chemistry, vol. 286, no. 50, pp. 43045-43053, 2011.

[5] A. O. Helbig, M. J. L. de Groot, R. A. van Gestel et al., "A three-way proteomics strategy allows differential analysis of yeast mitochondrial membrane protein complexes under anaerobic and aerobic conditions," Proteomics, vol. 9, no. 20, pp. 4787-4798, 2009.

[6] L. Böttinger, S. E. Horvath, T. Kleinschroth et al., "Phosphatidylethanolamine and cardiolipin differentially affect the stability of mitochondrial respiratory chain supercomplexes," Journal of Molecular Biology, vol. 423, no. 5, pp. 677-686, 2012.

[7] J. E. Vance and G. Tasseva, "Formation and function of phosphatidylserine and phosphatidylethanolamine in mammalian cells," Biochimica et Biophysica Acta (BBA)- 
Molecular and Cell Biology of Lipids, vol. 1831, no. 3, pp. 543-554, 2013.

[8] A. Görlach, E. Y. Dimova, A. Petry et al., "Reactive oxygen species, nutrition, hypoxia and diseases: problems solved?," Redox Biology, vol. 6, pp. 372-385, 2015.

[9] M. P. Murphy and R. A. J. Smith, "Targeting antioxidants to mitochondria by conjugation to lipophilic cations," Annual Review of Pharmacology and Toxicology, vol. 47, pp. 629-656, 2007.

[10] B. B. Lowell and G. I. Shulman, "Mitochondrial dysfunction and type 2 diabetes," Science, vol. 307, no. 5708, pp. 384-387, 2005.

[11] K. Morino, K. F. Petersen, and G. I. Shulman, "Molecular mechanisms of insulin resistance in humans and their potential links with mitochondrial dysfunction," Diabetes, vol. 55, no. 2, pp. S9-S15, 2006.

[12] J. A. Brignone, C. M. C. de Brignone, R. R. Rodriguez, B. N. Badano, and A. O. M. Stoppani, "Modified oscillation behavior and decreased D-3-hydroxybutyrate dehydrogenase activity in diabetic rat liver mitochondria," Archives of Biochemistry and Biophysics, vol. 214, no. 2, pp. 581-588, 1982.

[13] J. A. Brignone, C. M. C. de Brignone, C. R. Ricci, I. R. de Mignone, M. C. Susemihl, and R. R. Rodríguez, "Favourable, significant effect of the dose-dependent treatment with RU 38486 (RU) on the alterations of the hepatic mitochondrial function of diabetic rats," Diabetes Research and Clinical Practice, vol. 32, no. 3, pp. 141-148, 1996.

[14] H. Raza and A. John, "Implications of altered glutathione metabolism in aspirin-induced oxidative stress and mitochondrial dysfunction in HepG2 cells," PLoS One, vol. 7, no. 4, article e36325, 2012.

[15] G. K. Bandyopadhyay, G. Y. Joseph, J. Ofrecio, and J. M. Olefsky, "Increased malonyl-CoA levels in muscle from obese and type 2 diabetic subjects lead to decreased fatty acid oxidation and increased lipogenesis; thiazolidinedione treatment reverses these defects," Diabetes, vol. 55, no. 8, pp. 2277-2285, 2006.

[16] J. G. Duncan, "Mitochondrial dysfunction in diabetic cardiomyopathy," Biochimica et Biophysica Acta (BBA)Molecular Cell Research, vol. 1813, no. 7, pp. 1351-1359, 2011.

[17] L. Rato, A. I. Duarte, G. D. Tomás et al., "Pre-diabetes alters testicular PGC1- $\alpha /$ SIRT3 axis modulating mitochondrial bioenergetics and oxidative stress," Biochimica et Biophysica Acta (BBA)-Bioenergetics, vol. 1837, no. 3, pp. 335-344, 2014.

[18] W. C. Parks and R. L. Drake, "Insulin mediates the stimulation of pyruvate kinase by a dual mechanism," Biochemical Journal, vol. 208, no. 2, pp. 333-337, 1982.

[19] G. Antoun, F. McMurray, A. B. Thrush et al., "Erratum to: Impaired mitochondrial oxidative phosphorylation and supercomplex assembly in rectus abdominis muscle of diabetic obese individuals," Diabetologia, vol. 59, no. 2, pp. 396-397, 2016.

[20] C. D. Berdanier, H. B. Everts, C. Hermoyian, and C. E. Mathews, "Role of vitamin A in mitochondrial gene expression," Diabetes Research and Clinical Practice, vol. 54, no. 2, pp. S11-S27, 2001.

[21] D. Loven, H. Schedl, H. Wilson et al., "Effect of insulin and oral glutathione on glutathione levels and superoxide dismutase activities in organs of rats with streptozocin-induced diabetes," Diabetes, vol. 35, no. 5, pp. 503-507, 1986.

[22] P. S. Samiec, C. Drews-Botsch, E. W. Flagg et al., "Glutathione in human plasma: decline in association with aging, age-related macular degeneration, and diabetes," Free Radical Biology and Medicine, vol. 24, no. 5, pp. 699-704, 1998.

[23] A. Abd El Latif, B. E. S. El Bialy, H. D. Mahboub, and M. A. Abd Eldaim, "Moringa oleifera leaf extract ameliorates alloxan-induced diabetes in rats by regeneration of $\beta$ cells and reduction of pyruvate carboxylase expression," Biochemistry and Cell Biology, vol. 92, no. 5, pp. 413-419, 2014.

[24] S. Sreelatha and P. R. Padma, "Antioxidant activity and total phenolic content of Moringa oleifera leaves in two stages of maturity," Plant Foods for Human Nutrition, vol. 64, no. 4, pp. 303-311, 2009.

[25] P. Chumark, P. Khunawat, Y. Sanvarinda et al., "The in vitro and ex vivo antioxidant properties, hypolipidaemic and antiatherosclerotic activities of water extract of Moringa oleifera Lam. leaves," Journal of Ethnopharmacology, vol. 116, no. 3, pp. 439-446, 2008.

[26] A. L. Al-Malki and H. A. El Rabey, "The antidiabetic effect of low doses of Moringa oleifera Lam. seeds on streptozotocin induced diabetes and diabetic nephropathy in male rats," BioMed Research International, vol. 2015, Article ID 381040, 13 pages, 2015.

[27] D. J. Dorta, A. A. Pigoso, F. E. Mingatto et al., "The interaction of flavonoids with mitochondria: effects on energetic processes," Chemico-Biological Interactions, vol. 152, no. 2-3, pp. 67-78, 2005.

[28] I. Elingold, M. P. Isollabella, M. B. Casanova et al., "Mitochondrial toxicity and antioxidant activity of a prenylated flavonoid isolated from Dalea elegans," Chemico-Biological Interactions, vol. 171, no. 3, pp. 294-305, 2008.

[29] R. Lagoa, I. Graziani, C. Lopez-Sanchez, V. Garcia-Martinez, and C. Gutierrez-Merino, "Complex I and cytochrome $c$ are molecular targets of flavonoids that inhibit hydrogen peroxide production by mitochondria," Biochimica et Biophysica Acta (BBA)-Bioenergetics, vol. 1807, no. 12, pp. 1562-1572, 2011.

[30] N. Madi, M. Dany, S. Abdoun, and J. Usta, "Moringa oleifera's nutritious aqueous leaf extract has anticancerous effects by compromising mitochondrial viability in an ROS-dependent manner," Journal of the American College of Nutrition, vol. 35, no. 7, pp. 604-613, 2016.

[31] W. Khan, R. Parveen, K. Chester, S. Parveen, and S. Ahmad, "Hypoglycemic potential of aqueous extract of Moringa oleifera leaf and in vivo GC-MS metabolomics," Frontiers in Pharmacology, vol. 8, p. 577, 2017.

[32] R. Hovius, H. Lambrechts, K. Nicolay, and B. de Kruijff, "Improved methods to isolate and subfractionate rat liver mitochondria. Lipid composition of the inner and outer membrane," Biochimica et Biophysica Acta (BBA)-Biomembranes, vol. 1021, no. 2, pp. 217-226, 1990.

[33] E. Sierra-Campos, I. Velazquez, D. Matuz-Mares, A. Villavicencio-Queijeiro, and J. P. Pardo, "Functional properties of the Ustilago maydis alternative oxidase under oxidative stress conditions," Mitochondrion, vol. 9, no. 2, pp. 96-102, 2009.

[34] D. D. L. R. Castillo, M. Zarco-Zavala, S. Olvera-Sanchez et al., "Atypical cristae morphology of human syncytiotrophoblast mitochondria role for complex V," Journal of Biological Chemistry, vol. 286, no. 27, pp. 23911-23919, 2011.

[35] M. Esparza-Perusquía, S. Olvera-Sánchez, J. P. Pardo, G. Mendoza-Hernández, F. Martínez, and O. Flores-Herrera, "Structural and kinetics characterization of the $\mathrm{F}_{1} \mathrm{~F}_{0}$-ATP synthase dimer. New repercussion of monomer-monomer contact," Biochimica et Biophysica Acta (BBA)-Bioenergetics, vol. 1858, no. 12, pp. 975-981, 2017. 
[36] H. Schägger and G. von Jagow, "Blue native electrophoresis for isolation of membrane protein complexes in enzymatically active form," Analytical Biochemistry, vol. 199, no. 2, pp. 223-231, 1991.

[37] I. Wittig, M. Karas, and H. Schägger, "High resolution clear native electrophoresis for in-gel functional assays and fluorescence studies of membrane protein complexes," Molecular \& Cellular Proteomics, vol. 6, no. 7, pp. 1215-1225, 2007.

[38] I. Wittig and H. Schägger, "Electrophoretic methods to isolate protein complexes from mitochondria," Methods in Cell Biology, vol. 80, pp. 723-741, 2007.

[39] S. J. Couoh-Cardel, S. Uribe-Carvajal, S. Wilkens, and J. J. García-Trejo, "Structure of dimeric $\mathrm{F}_{1} \mathrm{~F}_{0}$-ATP synthase," Journal of Biological Chemistry, vol. 285, no. 47, pp. 3644736455, 2010.

[40] U. K. Laemmli, "Cleavage of structural proteins during the assembly of the head of bacteriophage T4," Nature, vol. 227, no. 5259, pp. 680-685, 1970.

[41] O. H. Lowry, N. J. Rosebrough, A. L. Farr, and R. J. Randall, "Protein measurement with the Folin phenol reagent," Journal of Biological Chemistry, vol. 193, no. 1, pp. 265-275, 1951.

[42] O. Yilmaz, S. Keser, M. Tuzcu et al., "A practical HPLC method to measure reduced (GSH) and oxidized (GSSG) glutathione concentrations in animal tissues," Journal of Animal and Veterinary Advances, vol. 8, no. 2, pp. 343-347, 2009.

[43] J. A. Buege and S. D. Aust, "Microsomal lipid peroxidation," Methods in Enzymology, vol. 52, pp. 302-310, 1978.

[44] A. A. Starkov, "Measurement of Mitochondrial ROS Production," in Protein Misfolding and Cellular Stress in Disease and Aging. Methods in Molecular Biology (Methods and Protocols), P. Bross and N. Gregersen, Eds., vol. 648, pp. 245-255, Springer, New York, NY, USA, 2010.

[45] R. L. Levine, D. Garland, C. N. Oliver et al., "Determination of carbonyl content in oxidatively modified proteins," Methods in Enzymology, vol. 186, pp. 464-478, 1990.

[46] P. Naughton, R. Foresti, S. K. Bains, M. Hoque, C. J. Green, and R. Motterlini, "Induction of heme oxygenase 1 by nitrosative stress. A role for nitroxyl anion," Journal of Biological Chemistry, vol. 277, no. 43, pp. 40666-40674, 2002.

[47] P. Kiranmayi and B. Babitha, "Effect of Moringa oleifera Leaf powder on blood glucose levels in type II diabetes mellitus patients," Vegetos-An International Journal of Plant Research, vol. 24, no. 2, pp. 114-116, 2011.

[48] P. Anthanont, N. Lumlerdkij, P. Akarasereenont, S. Vannasaeng, and A. Sriwijitkamol, "Moringa oleifera leaf increases insulin secretion after single dose administration: a preliminary study in healthy subjects," Journal of the Medical Association of Thailand, vol. 99, no. 3, pp. 308-313, 2016.

[49] A. C. Maritim, R. A. Sanders, and J. B. Watkins III, "Effects of $\alpha$-lipoic acid on biomarkers of oxidative stress in streptozotocin-induced diabetic rats," Journal of Nutritional Biochemistry, vol. 14, no. 5, pp. 288-294, 2003.

[50] A. C. Maritim, R. A. Sanders, and J. B. Watkins III, "Diabetes, oxidative stress, and antioxidants: a review," Journal of Biochemical and Molecular Toxicology, vol. 17, no. 1, pp. 24-38, 2003.

[51] A. B. Egorova, Y. A. Uspenskaya, and V. P. Nefedov, "NAD and glutathione modulate sensitivity of bone marrow cells to oxidative stress," Bulletin of Experimental Biology and Medicine, vol. 132, no. 1, pp. 637-640, 2001.
[52] W. Völkel, R. Alvarez-Sánchez, I. Weick, A. Mallya, W. Dekanta, and A. Pähler, "Glutathione conjugates of 4-hydroxy-2 (E)-nonenal as biomarkers of hepatic oxidative stress-induced lipid peroxidation in rats," Free Radical Biology and Medicine, vol. 38, no. 11, pp. 1526-1536, 2005.

[53] R. Tenhunen, H. S. Marver, and R. Schmid, "The enzymatic conversion of heme to bilirubin by microsomal heme oxygenase," Proceedings of the National Academy of Sciences, vol. 61, no. 2, pp. 748-755, 1968.

[54] R. K. Kutty and M. D. Maines, "Purification and characterization of biliverdin reductase from rat liver," Journal of Biological Chemistry, vol. 256, no. 8, pp. 3956-3962, 1981.

[55] M. A. Di Noia, S. Van Driesche, F. Palmieri et al., "Heme oxygenase-1 enhances renal mitochondrial transport carriers and cytochrome $c$ oxidase activity in experimental diabetes," Journal of Biological Chemistry, vol. 281, no. 23, pp. 1568715693, 2006.

[56] D. Jaiswal, P. K. Rai, S. Mehta et al., "Role of Moringa oleifera in regulation of diabetes-induced oxidative stress," Asian Pacific Journal of Tropical Medicine, vol. 6, no. 6, pp. 426432, 2013.

[57] R. Gupta, M. Mathur, V. K. Bajaj et al., "Evaluation of antidiabetic and antioxidant activity of Moringa oleifera in experimental diabetes," Journal of Diabetes, vol. 4, no. 2, pp. 164-171, 2012.

[58] A. F. Santos, A. C. Argolo, P. M. Paiva, and L. C. Coelho, "Antioxidant activity of Moringa oleifera tissue extracts," Phytotherapy Research, vol. 26, no. 9, pp. 1366-1370, 2012.

[59] C. S. T. Origassa and N. O. S. Câmara, "Cytoprotective role of heme oxygenase- 1 and heme degradation derived end products in liver injury," World Journal of Hepatology, vol. 5, no. 10, p. 541, 2013.

[60] D. Jaiswal, P. K. Rai, A. Kumar, S. Mehta, and G. Watal, "Effect of Moringa oleifera Lam. leaves aqueous extract therapy on hyperglycemic rats," Journal of Ethnopharmacology, vol. 123, no. 3, pp. 392-396, 2009.

[61] S. Adisakwattana and B. Chanathong, "Alpha-glucosidase inhibitory activity and lipid-lowering mechanisms of Moringa oleifera leaf extract," European Review for Medical and Pharmacological Sciences, vol. 15, no. 7, pp. 803-808, 2011.

[62] F. M. Ferreira, C. M. Palmeira, R. Seiça, A. J. Moreno, and M. S. Santos, "Diabetes and mitochondrial bioenergetics: alterations with age," Journal of Biochemical and Molecular Toxicology, vol. 17, no. 4, pp. 214-222, 2003.

[63] S. Ardestani, D. L. Deskins, and P. P. Young, "Membrane TNF-alpha-activated programmed necrosis is mediated by Ceramide-induced reactive oxygen species," Journal of Molecular Signaling, vol. 8, p. 12, 2013.

[64] D.-D. Zhao, N. Yu, X.-K. Li et al., "Antidiabetic and antioxidative effect of Jiang Tang Xiao Ke granule in high-fat diet and low-dose streptozotocin induced diabetic rats," Evidence-Based Complementary and Alternative Medicine, vol. 2014, Article ID 475192, 8 pages, 2014.

[65] E. K. Ainscow and M. D. Brand, "Top-down control analysis of ATP turnover, glycolysis and oxidative phosphorylation in rat hepatocytes," FEBS Journal, vol. 263, no. 3, pp. 671-685, 1999.

[66] C. Desler, T. L. Hansen, J. B. Frederiksen, M. L. Marcker, K. K. Singh, and L. J. Rasmussen, "Is there a link between mitochondrial reserve respiratory capacity and aging?," Journal of Aging Research, vol. 2012, Article ID 192503, 9 pages, 2012.

[67] D. A. Rendon, K. Kotedia, S. F. Afshar et al., "Mapping radiation injury and recovery in bone marrow using ${ }^{18} \mathrm{~F}$-FLT 
PET/CT and USPIO MRI in a rat model," Journal of Nuclear Medicine, vol. 57, no. 2, pp. 266-271, 2016.

[68] T. Lobo-Jarne and C. Ugalde, "Respiratory chain supercomplexes: structures, function and biogenesis," Seminars in Cell \& Developmental Biology, 2017, in press.

[69] R. Guo, S. Zong, M. Wu, J. Gu, and M. Yang, "Architecture of human mitochondrial respiratory megacomplex $\mathrm{I}_{2} \mathrm{III}_{2} \mathrm{IV}_{2}$," Cell, vol. 170, no. 6, pp. 1247-1257, 2017.

[70] D. R. Winge, "Sealing the mitochondrial respirasome," Molecular and Cellular Biology, vol. 32, no. 14, pp. 26472652, 2012.

[71] G. Lenaz and M. L. Genova, "Supramolecular organisation of the mitochondrial respiratory chain: a new challenge for the mechanism and control of oxidative phosphorylation," Advances in Experimental Medicine and Biology, vol. 748, pp. 107-144, 2012.

[72] G. Antoun, F. McMurray, A. B. Thrush et al., "Impaired mitochondrial oxidative phosphorylation and supercomplex assembly in rectus abdominis muscle of diabetic obese individuals," Diabetologia, vol. 58, no. 12, pp. 2861-2866, 2015.

[73] C. Oswald, U. Krause-Buchholz, and G. Rödel, "Knockdown of human COX17 affects assembly and supramolecular organization of cytochrome c oxidase," Journal of Molecular Biology, vol. 389, no. 3, pp. 470-479, 2009.

[74] C. R. Lundin, C. von Ballmoos, M. Ott, P. Ädelrotha, and P. Brzezinski, "Regulatory role of the respiratory supercomplex factors in Saccharomyces cerevisiae," Proceedings of the National Academy of Sciences of the United States of America, vol. 113, no. 31, pp. E4476-E4485, 2016.

[75] R. K. Singhal, C. Kruse, J. Heidler et al., "Coil is a novel assembly factor of the yeast complex III-complex IV supercomplex," Molecular Biology of the Cell, vol. 28, no. 20, pp. 2609-2622, 2017.

[76] R. Pérez-Pérez, T. Lobo-Jarne, D. Milenkovic et al., "COX7A2L is a mitochondrial complex III binding protein that stabilizes the $\mathrm{III}_{2}+\mathrm{IV}$ supercomplex without affecting respirasome formation," Cell Reports, vol. 16, no. 9, pp. 2387-2398, 2016.

[77] M. G. Rosca, E. J. Vazquez, J. Kerner et al., "Cardiac mitochondria in heart failure: decrease in respirasomes and oxidative phosphorylation," Cardiovascular Research, vol. 80, no. 1, pp. 30-39, 2008.

[78] D. Galati, S. Srinivasan, H. Raza et al., "Role of nuclearencoded subunit $\mathrm{Vb}$ in the assembly and stability of cytochrome $c$ oxidase complex: implications in mitochondrial dysfunction and ROS production," Biochemical Journal, vol. 420, no. 3, pp. 439-449, 2009.

[79] A. A. Aloud, C. Veeramani, C. Govindasamy, M. A. Alsaif, A. S. El Newehy, and K. S. Al-Numair, "Galangin, a dietary flavonoid, improves antioxidant status and reduces hyperglycemia-mediated oxidative stress in streptozotocininduced diabetic rats," Redox Report, vol. 22, no. 6, pp. 290-300, 2017.

[80] V. B. Ritov, E. V. Menshikova, K. Azuma et al., "Deficiency of electron transport chain in human skeletal muscle mitochondria in type 2 diabetes mellitus and obesity," American Journal of Physiology-Endocrinology and Metabolism, vol. 298, no. 1, pp. E49-E58, 2010.

[81] S.-E. Kim, R. Mori, T. Komatsu et al., "Upregulation of cytochrome c oxidase subunit $6 \mathrm{~b} 1$ (Cox6b1) and formation of mitochondrial supercomplexes: implication of Cox6b1 in the effect of calorie restriction," Age, vol. 37, no. 3, p. 45, 2015.

[82] S. Bansal, M. Siddarth, D. Chawla, B. D. Banerjee, S. V. Madhu, and A. K. Tripathi, "Advanced glycation end products enhance reactive oxygen and nitrogen species generation in neutrophils in vitro," Molecular and Cellular Biochemistry, vol. 361, no. 1-2, pp. 289-296, 2012.

[83] Y. Li, J.-S. Park, J.-H. Deng, and Y. Bai, "Cytochrome c oxidase subunit IV is essential for assembly and respiratory function of the enzyme complex," Journal of Bioenergetics and Biomembranes, vol. 38, no. 5-6, pp. 283-291, 2006.

[84] H. Schägger, R. de Coo, M. F. Bauer, S. Hofmann, C. Godinot, and U. Brandt, "Significance of respirasomes for the assembly/stability of human respiratory chain complex I," Journal of Biological Chemistry, vol. 279, no. 35, pp. 36349-36353, 2004.

[85] S. Budde, L. van den Heuvel, R. Smeets et al., "Clinical heterogeneity in patients with mutations in the NDUFS4 gene of mitochondrial complex I," Journal of Inherited Metabolic Disease, vol. 26, no. 8, pp. 813-815, 2003.

[86] S. Scacco, V. Petruzzella, S. Budde et al., "Pathological mutations of the human NDUFS4 gene of the $18-\mathrm{kDa}$ (AQDQ) subunit of complex I affect the expression of the protein and the assembly and function of the complex," Journal of Biological Chemistry, vol. 278, no. 45, pp. 4416144167, 2003.

[87] P. Cardol, L. Boutaffala, S. Memmi, B. Devreese, R. F. Matagnea, and C. Remaclea, "In Chlamydomonas, the loss of ND5 subunit prevents the assembly of whole mitochondrial complex I and leads to the formation of a low abundant $700 \mathrm{kDa}$ subcomplex," Biochimica et Biophysica Acta (BBA)-Bioenergetics, vol. 1777, no. 4, pp. 388-396, 2008.

[88] M. Brownlee, "The pathobiology of diabetic complications," Diabetes, vol. 54, no. 6, pp. 1615-1625, 2005.

[89] M. R. Duchen, "Roles of mitochondria in health and disease," Diabetes, vol. 53, no. 1, pp. S96-S102, 2004.

[90] J. A. Herlein, B. D. Fink, Y. O’Malley, and W. I. Sivitz, "Superoxide and respiratory coupling in mitochondria of insulin-deficient diabetic rats," Endocrinology, vol. 150, no. 1, pp. 46-55, 2008.

[91] M. D. Brand, C. Affourtit, T. C. Esteves et al., "Mitochondrial superoxide: production, biological effects, and activation of uncoupling proteins," Free Radical Biology and Medicine, vol. 37, no. 6, pp. 755-767, 2004.

[92] L. K. Kwong and R. S. Sohal, "Substrate and site specificity of hydrogen peroxide generation in mouse mitochondria," Archives of Biochemistry and Biophysics, vol. 350, no. 1, pp. 118-126, 1998.

[93] B. Kadenbach, "Intrinsic and extrinsic uncoupling of oxidative phosphorylation," Biochimica et Biophysica Acta (BBA)-Bioenergetics, vol. 1604, no. 2, pp. 77-94, 2003.

[94] A. Musatov and N. C. Robinson, "Susceptibility of mitochondrial electron-transport complexes to oxidative damage. Focus on cytochrome c oxidase," Free Radical Research, vol. 46, no. 11, pp. 1313-1326, 2012.

[95] A. J. Lambert and M. D. Brand, "Inhibitors of the quinonebinding site allow rapid superoxide production from mitochondrial NADH: ubiquinone oxidoreductase (complex I)," Journal of Biological Chemistry, vol. 279, no. 38, pp. 3941439420, 2004.

[96] S. Raha and B. H. Robinson, "Mitochondria, oxygen free radicals, disease and ageing," Trends in Biochemical Sciences, vol. 25, no. 10, pp. 502-508, 2000.

[97] J. Wu, X. Luo, N. Thangthaeng et al., "Pancreatic mitochondrial complex I exhibits aberrant hyperactivity in diabetes," Biochemistry and Biophysics Reports, vol. 11, pp. 119-129, 2017. 
[98] H. Raza, S. K. Prabu, A. John, and N. G. Avadhani, "Impaired mitochondrial respiratory functions and oxidative stress in streptozotocin-induced diabetic rats," International Journal of Molecular Sciences, vol. 12, no. 5, pp. 3133-3147, 2011.

[99] J. Škrha Jr., M. Kalousová, J. Švarcová et al., "Relationship of soluble RAGE and RAGE ligands HMGB1 and EN-RAGE to endothelial dysfunction in type 1 and type 2 diabetes mellitus," Experimental and Clinical Endocrinology \& Diabetes, vol. 120, no. 5, pp. 277-281, 2012.

[100] O. Demin, H. Westerhoff, and B. Kholodenko, "Mathematical modelling of superoxide generation with the bc1 complex of mitochondria," Biochemistry. Biokhimiia, vol. 63, no. 6, pp. 634-649, 1998.

[101] L. Gibellini, E. Bianchini, S. De Biasi, M. Nasi, A. Cossarizza, and M. Pinti, "Natural compounds modulating mitochondrial functions," Evidence-Based Complementary and Alternative Medicine, vol. 2015, Article ID 527209, 13 pages, 2015.

[102] C. Sandoval-Acuña, J. Ferreira, and H. Speisky, "Polyphenols and mitochondria: an update on their increasingly emerging ROS-scavenging independent actions," Archives of Biochemistry and Biophysics, vol. 559, pp. 75-90, 2014.

[103] L. Raudone, D. Burdulis, R. Raudonis et al., "Effect of Perilla Frutescens extracts and rosmarinic acid on rat heart mitochondrial functions," Acta Poloniae Pharmaceutica, vol. 73, no. 1, pp. 135-145, 2016.

[104] G. B. Melo, R. L. Silva, V. A. Melo et al., "Effect of the aqueous extract of Hyptis pectinata on liver mitochondrial respiration," Phytomedicine, vol. 12, no. 5, pp. 359-362, 2005. 


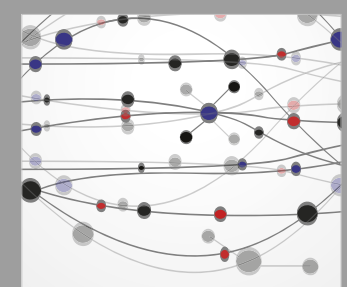

The Scientific World Journal
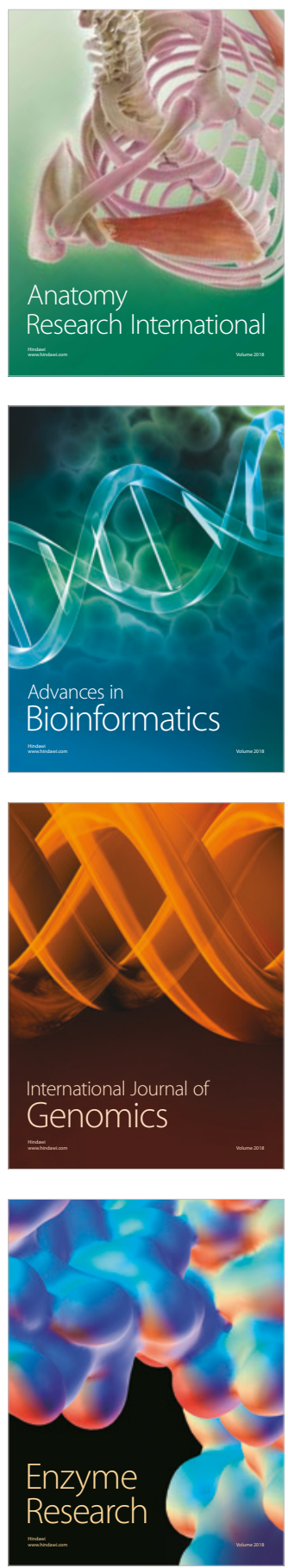
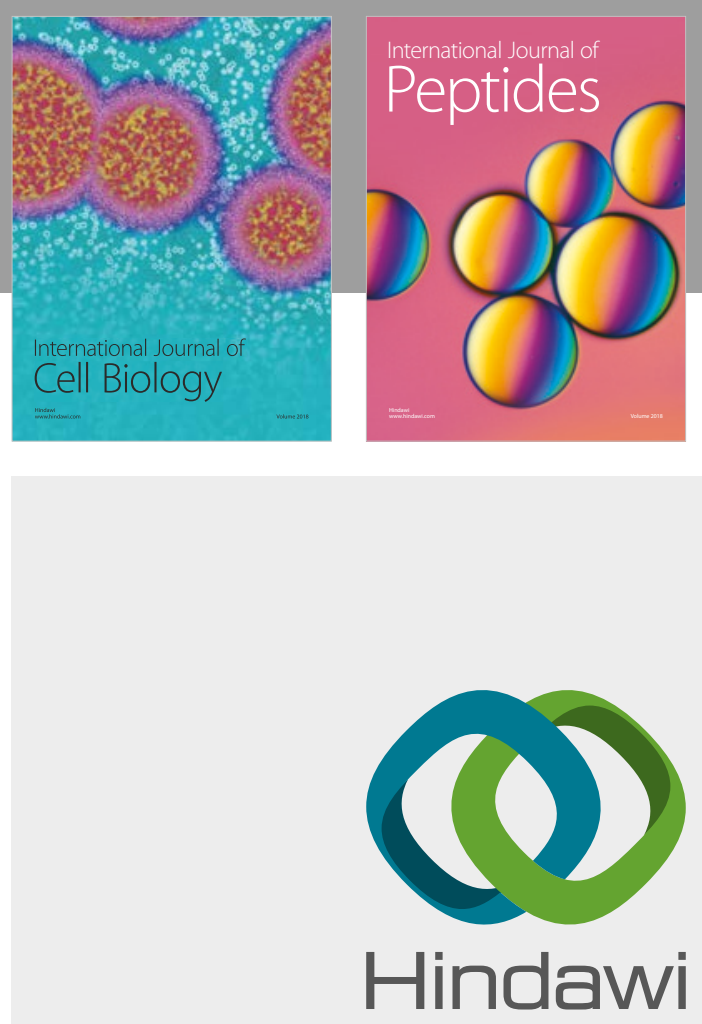

Submit your manuscripts at

www.hindawi.com
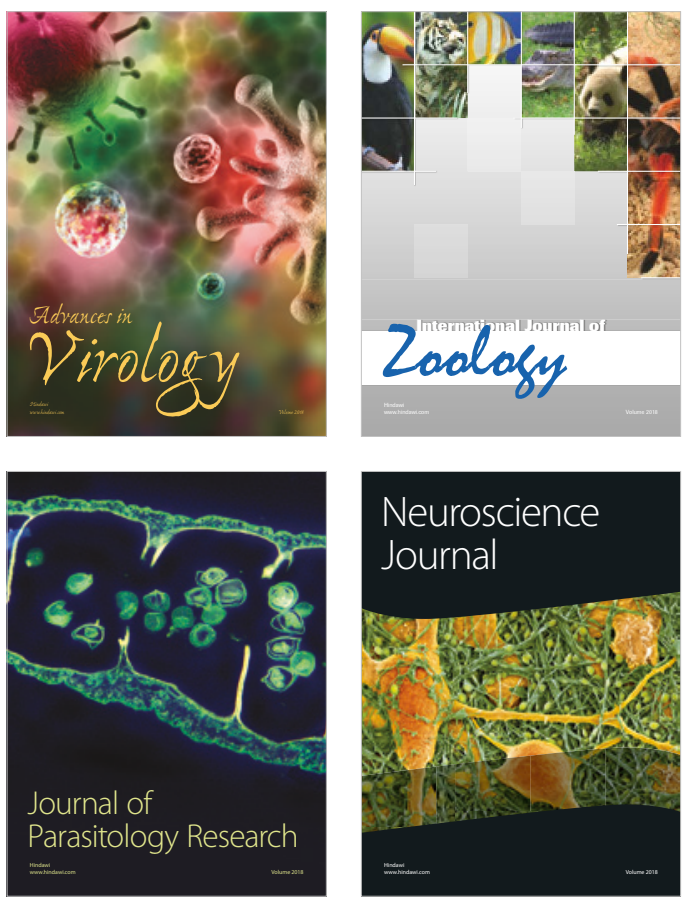
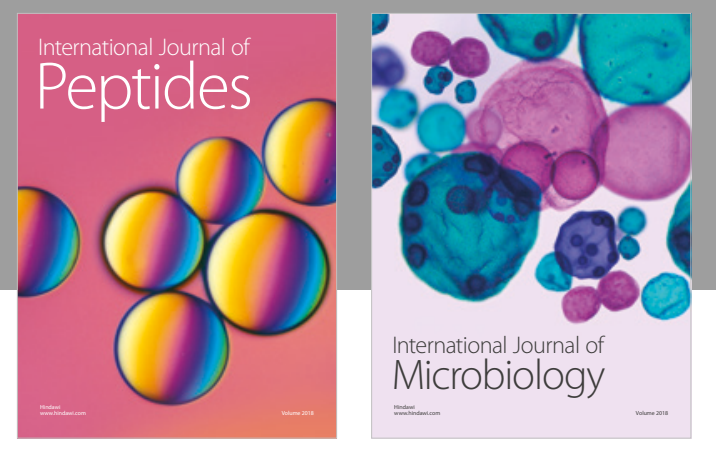

nternational Journal of Microbiology
Journal of
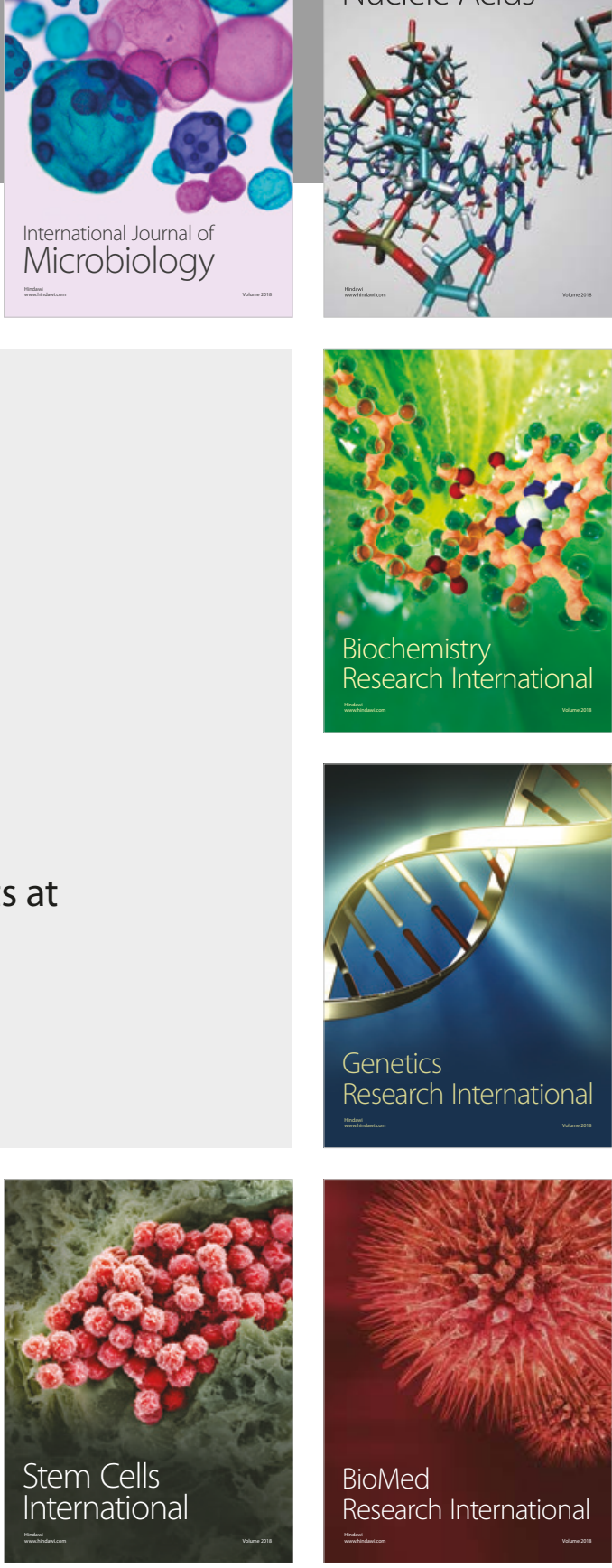
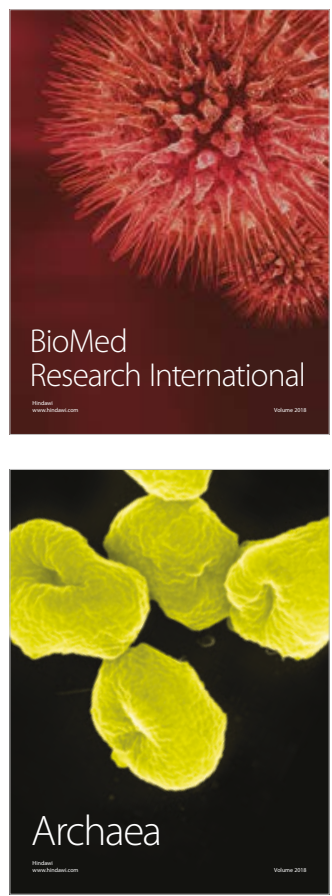